\title{
Infrared Imagery of Crown-Fire Dynamics during FROSTFIRE
}

\author{
JANICE COEN \\ National Center for Atmospheric Research, * Boulder, Colorado \\ SHANKAR MAHALINGAM \\ University of California, Riverside, Riverside, California \\ JOHN DAILY \\ University of Colorado at Boulder, Boulder, Colorado
}

(Manuscript received 28 August 2003, in final form 6 April 2004)

\section{ABSTRACT}

\begin{abstract}
A thorough understanding of crown-fire dynamics requires a clear picture of the three-dimensional winds in and near the fire, including the flaming combustion zone and the convective updrafts produced by the fire. These observations and analyses present a unique high-spatial-resolution and high-temporal-resolution perspective of the motions within crown fires propagating up a forested $20^{\circ}$ slope under light winds of $3 \mathrm{~m} \mathrm{~s}^{-1}$ during the FROSTFIRE experiment in interior Alaska. The purpose of this work is to calculate combustion-zone winds and examine mechanisms for the rapid propagation of crown fires. An infrared imager was used to detect hightemperature regions produced by incandescent soot particles in and near the fire and to produce a sequence of high-frequency $(60 \mathrm{~Hz})$, high-resolution $(0.375 \mathrm{~m} \times 0.8 \mathrm{~m})$ two-dimensional images of temperature. An imageflow-analysis technique was applied to these data to derive wind fields in the image plane. Maximum updrafts of 32-60 m s $\mathrm{m}^{-1}$ accompany maximum downdrafts of $18-30 \mathrm{~m} \mathrm{~s}^{-1}$. Horizontal wind speeds of $12-28 \mathrm{~m} \mathrm{~s}^{-1}$ show strong inflow into the base of the convective updrafts and imply recirculation of air and incomplete combustion products from the fire. Motions were more complex than a single large convective plume or many buoyant treescale plumes rising separately. Instead, repeated examples of narrow flaming fingers, representing a scale larger than individual trees, initially burst upslope along the ground for tens of meters at speeds up to $28-48 \mathrm{~m} \mathrm{~s}^{-1}$ before turning upward. These bursts exceeded ambient environmental winds, those considered to be driving the fire, by a factor of 10 and were low enough to propagate the crown fire actively by both igniting and preheating/ drying canopy fuel ahead of the fire. Average spread rates were $0.75-1.11 \mathrm{~m} \mathrm{~s}^{-1}$, with a peak 10 -s spread rate of $1.26 \mathrm{~m} \mathrm{~s}^{-1}$. This powerful, dynamic mechanism of fire spread could explain firefighter reports of being overtaken by "fireballs."
\end{abstract}

\section{Introduction}

Wildland fire exhibits a vast range of fire behavior, from smoldering ground fires, to quickly spreading grass fires, to flaming crown fires running through tree canopies. Crowning is an example of extreme fire behavior and is important from a fire management perspective because it represents an intensity of wildfire behavior that ordinarily precludes, or at least severely limits, direct suppression until conditions subside. Crown-fire spread rates can vary widely $\left(0-3.1 \mathrm{~m} \mathrm{~s}^{-1}\right.$, faster in

* The National Center for Atmospheric Research is sponsored by the National Science Foundation.

Corresponding author address: Janice Coen, National Center for Atmospheric Research, P.O. Box 3000, Boulder, CO 80307-3000. E-mail: janicec@ncar.ucar.edu mountainous terrain or when environmental winds are strong-Rothermel 1991; 0.131-0.455 $\mathrm{m} \mathrm{s}^{-1}$ on flat ground with ambient winds ranging from 10 to 16 $\mathrm{km} \mathrm{h}^{-1}$-Albini and Stocks 1986). Bessie and Johnson (1995) attribute most of this variability to weather factors rather than variability in fuel. Crown fires can spread at several times the rate of surface fires (Rothermel 1983, 1991) and can spot (i.e., can loft burning embers ahead of the fire to ignite new fires), leading to control problems at natural and anthropogenic fuel breaks. Predictability is difficult because such fires often affect their atmospheric environment, behaving erratically and sometimes dangerously (National Wildfire Coordinating Group 1994).

Some specific examples of this erratic behavior have been recorded in the International Crown Fire Modelling Experiment (ICFME), during which balls of fire were photographed bursting forward from a prescribed crown 


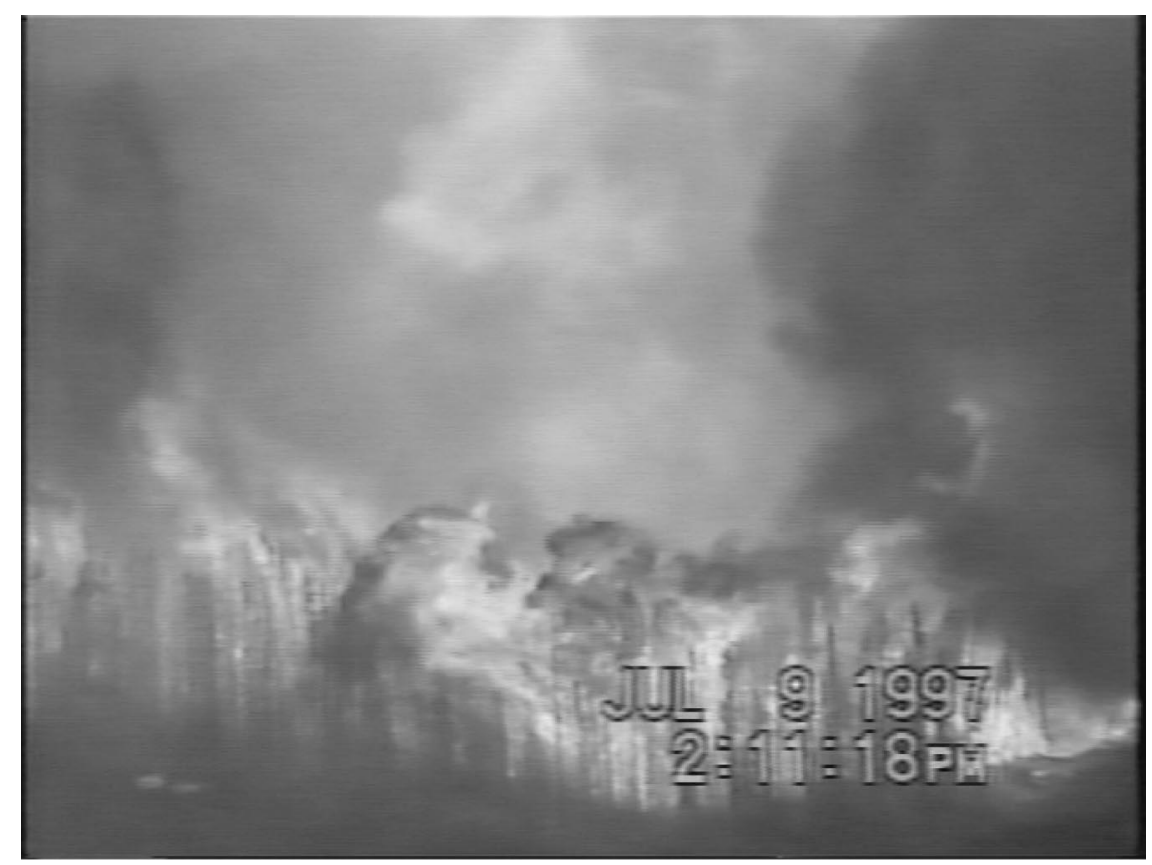

FIG. 1. Image of extreme fire behavior (forward burst) obtained during the ICFME (photo courtesy of the Canadian Forest Service).

fire burning through a plot of boreal forest (Fig. 1), and in the Wildland Fire Experiment (WiFE), during which a research aircraft captured infrared imagery of a finger of flame that appeared, from the overhead perspective, to shoot $100 \mathrm{~m}$ from the fire line at a speed estimated at $50 \mathrm{~m} \mathrm{~s}^{-1}$ (Radke et al. 2000) before collapsing. From this perspective, Radke et al. could not determine the burst's height above ground or determine unambiguously whether the path was forward or upward, although a second instrument on the aircraft confirmed that at least part of the burst left a trail of burning fuel on the ground, suggesting it was close to the surface. The mechanisms for this behavior are not understood well because few detailed observations of the motions inside crown fires have been made, visible imagery is often obscured by smoke, the phenomenon changes in fractions of a second, and coupled atmosphere-fire models (Clark et al. 1996a,b, 2004; Coen et al. 2001; Linn et al. 2002) are just beginning to replicate the phenomena that result from the complex interactions between a fire and its atmospheric environment.

A good understanding of fire behavior requires a clear picture of the three-dimensional winds in and near the fire, including the flaming combustion zone and the convective motions produced by the fire. These motions determine the convergence pattern superimposed upon the surface winds, which in turn direct and propagate the fire, produce the persistence and ubiquity of the "universal fire shape" (Albini 1993; Coen et al. 2001), and lead to the complex, nonlinear dynamics exemplified by fire whirls and the previously mentioned forward bursts. Clark et al. (1999) developed image-flow-anal- ysis methods to analyze infrared imager data and to study the very small temporal and spatial scales of motion in the prescribed crown fires set in boreal forest plots during ICFME. They found that updrafts between 10 and $30 \mathrm{~m} \mathrm{~s}^{-1}$, downdrafts between 10 and $20 \mathrm{~m} \mathrm{~s}^{-1}$, and horizontal motions between 5 and $15 \mathrm{~m} \mathrm{~s}^{-1}$ frequently occurred throughout the fire. The analysis also revealed pairs of counterrotating convective updrafts, rotating such that air between the towers blew forward, downwind in the direction of fire spread. They theorized that as these vertically oriented vortices tilt together, their combined motion causes the vortices to tip forward at a sharp angle, forming a hairpin-shaped vortex that causes a turbulent burst. This technique has also been applied in a laboratory setting to study motions within fire plumes (Zhou et al. 2003).

Here, infrared imagery obtained during the FROSTFIRE experiment is analyzed, during which time prescribed fires were set in the boreal forest of the CaribouPoker Creeks Research Watershed (CPCRW) Long-Term Ecological Research Program site in the Alaskan interior. Section 2 describes the FROSTFIRE experiment, the fire environment variables, and the fires. Section 3 describes the instrument used, the techniques for gathering and processing these data, and the image-flow-analysis method used to analyze these data. Section 4 describes our analysis of crown-fire runs to investigate crown-fire properties and propagation. The analysis shows bursts along the surface comparable to the magnitudes found by Radke et al. (2000), with wind velocities and sensible heat fluxes that represent extremes among atmospheric processes. Moreover, in this case these extreme velocities cannot be 
attributed to strong environmental winds. These results are discussed in section 5 .

\section{Field experiment description}

FROSTFIRE was a landscape-scale research project conducted in the boreal forest of interior Alaska that focused on the long-term ecological effects of fire. The research goals of FROSTFIRE were to understand the role of wildfire in Alaska and to develop an improved understanding of boreal feedbacks to climate. The setting was the CPCRW Long-Term Ecological Research Program site, a $104-\mathrm{km}^{2}$ basin approximately $40 \mathrm{~km}$ northeast of Fairbanks, near the town of Chatanika $\left(65^{\circ} 10^{\prime} \mathrm{N}, 147^{\circ} 30^{\prime} \mathrm{W}\right)$. Within the 1050 -ha perimeter, during the experiment, prescribed fires mimicking natural conditions burned 430 ha of mostly black spruce, leaving the hardwoods standing. Major burning occurred over 3 days (8-10 July 1999) while conditions were within the window of prescribed burning conditions, followed by several days of smoldering. For more details, see Hinzman et al. (2003) and Fastie et al. (2003).

\section{a. Terrain}

CPCRW is located in the Yukon-Tanana uplands in interior Alaska. Located between the Brooks and Alaska Ranges, CPCRW is part of a large area of rolling forested hills covered by boreal forest. Ridge elevations range from 450 to $900 \mathrm{~m}$, with rises of 150-500 $\mathrm{m}$ above the adjacent valleys. The topography in the area of the FROSTFIRE burn is shown in Figs. $2 \mathrm{a}$ and $2 \mathrm{~b}$. The dominant terrain features within the prescribed burn perimeter are Caribou Peak (773 m MSL) and Helmer's Ridge (630 m MSL), between which Little Poker Creek flows.

\section{b. Vegetation and fuel}

CPCRW is a permafrost-dominated watershed that contains the major forest types of the Alaskan boreal forest. Three primary types characterized the vegetation in the burn area. The first is closed and open coniferous forests of black spruce (Picea mariana; Fig. 2c). This highly flammable vegetation is the climax vegetation type on north slopes in the research area. They grow tall and thin, rarely exceeding $15 \mathrm{~m}$ in height or 0.25 $\mathrm{m}$ in diameter, and one-half of the trees in a stand may be less than $0.05 \mathrm{~m}$ in diameter. Based upon photos of the burn area, the treetops in the data field of view were approximately $10 \mathrm{~m}$ above ground and spaced closely together, with stems often only $2 \mathrm{~m}$ apart. Black spruce are not fire resistant-branches close to the ground and thin bark combine to make them particularly vulnerable to fire-and thus fire spread freely throughout the black spruce in this experiment. The remainder of the site was dominated by closed hardwood forests of paper birch (Betula paperifera) and quaking aspen (Populus tre- muloides) on south-facing slopes, boggy sphagnumdominated wetlands along the stream, and caribou moss (Cladonia rangifernia) on exposed ground. Dwarf tree scrub and tall scrub grow in the valley bottom and on some ridgelines.

Fuel loads given in the FROSTFIRE burn plan (Wilmore et al. 1998) were estimated using an aerial photo series and previously published data from other sites (Dymess et al. 1989). Based on these works, Wilmore et al. (1998) estimated that aerial biomass totaled approximately $5.16 \mathrm{~kg} \mathrm{~m}^{-2}$ and the forest floor totaled $12.3 \mathrm{~kg} \mathrm{~m}^{-2}$ in the black spruce stands. Above-ground biomass for the aspen and birch was estimated at 5.60 $\mathrm{kg} \mathrm{m}^{-2}$. Forest floor necromass was estimated as 7.85$10.8 \mathrm{~kg} \mathrm{~m}^{-2}$ for the birch and aspen stands.

\section{c. Weather}

The weather conditions recorded at two surface stations at CPCRW during the burn period are shown (Fig. 3 ). The data at the Caribou Peak (CPEAK) station represent exposed mountaintop conditions unaffected by the fire. The Cold Regions Research and Engineering Laboratory (CRREL) station was located at the mouth of the valley between Caribou Peak and Helmer's Ridge, about $1 \mathrm{~km}$ downstream from the fires (see Fig. 2b). The conditions at midday on 10 July 1999 in the area of the fire were approximately $20^{\circ}-25^{\circ} \mathrm{C}$, with $30 \%$ relative humidity and winds from the northeast at 2-4 $\mathrm{m} \mathrm{s}^{-1}$. The flows were upslope as the ground began warming in the sun.

\section{d. Fire}

A 10-m-wide fire line was cut and brush was removed from the entire perimeter of the FROSTFIRE burn site, and then it was blacklined (all vegetation was burned by hand torches down to mineral soil) before the prescribed fire. Burning occurred over a 3-day period from 8 to 10 July 1999 , followed by several days of smoldering. The experiment was designed to vary fire intensity across the watershed to span the entire range of burn intensities observed in boreal forest. After 1.5 days of blacklining, interior aerial ignition began at approximately 1900 LST 9 July with "ping-pong" ignition (small spheres containing potassium permanganate were injected with ethylene glycol and jettisoned from the helicopter before the chemicals reacted thermally to produce a flame) and terra torching (a giant drip torch, fueled by a drum of gelled gasoline and suspended from a helicopter, emitted a steady stream of burning fuel globs) and ended at approximately 2100 LST when the relative humidity became too high and the fuels resisted ignition. These ignitions subsided overnight.

The 10 July operational plan called for more firing, and, as of 1100 LST, only small fires were smoldering from the previous night's ignitions. Then, as the solar heating increased, the northeasterly wind increased, fan- 
(a)

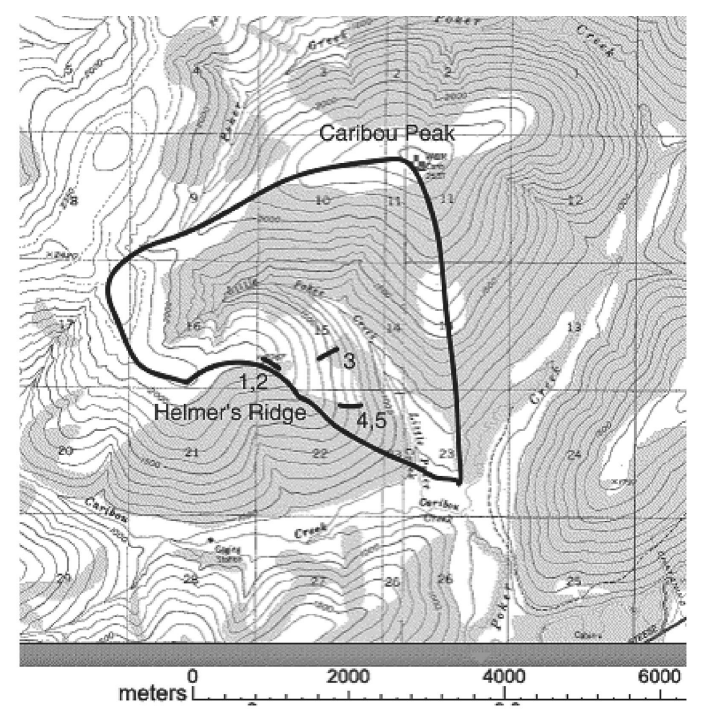

(b)

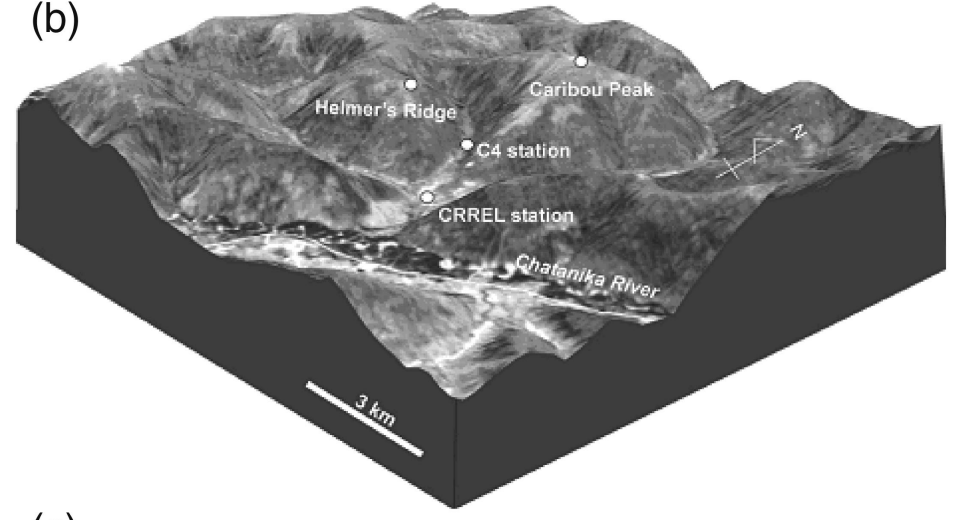

(c)

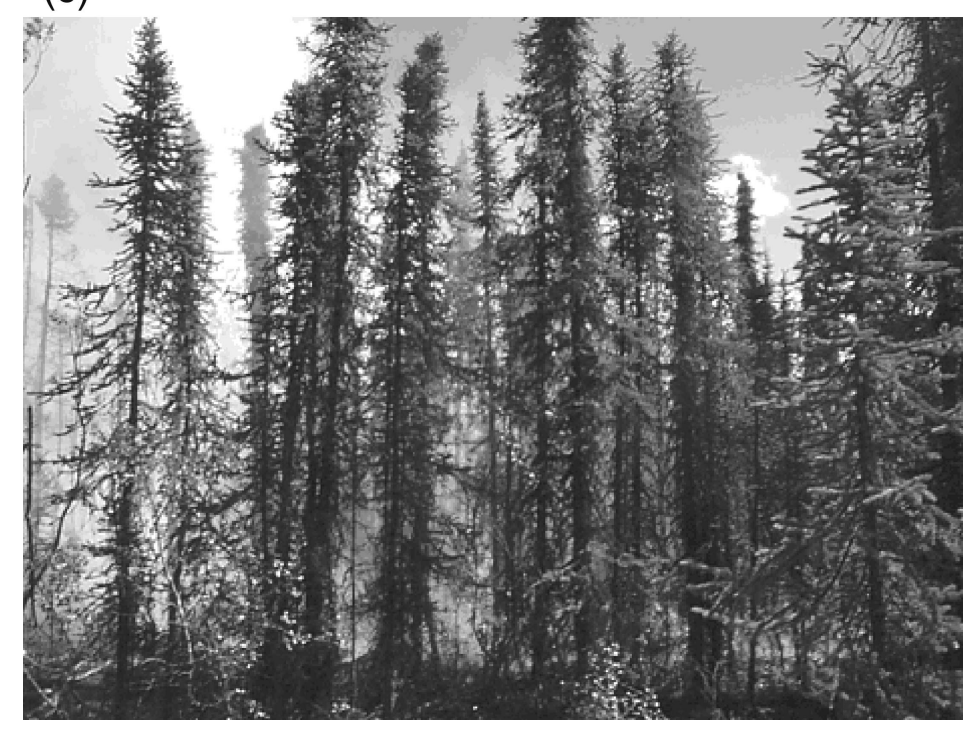

FIG. 2. (a) Terrain with locations of Caribou Peak (imager location) and location of the data cross sections (i.e., the image plane) of sequences 1-5. The thick contour shows the FROSTFIRE burn perimeter. (b) Local terrain with locations of surface stations (courtesy of Larry Hinzman, University of Alaska, Fairbanks). (c) Typical black spruce distribution during blacklining on 8 Jul 1999 near station C4 [see (b)] (photo courtesy of U.S. Department of Agriculture Forest Service Research). 
SURFACE STATION WINDSPEED

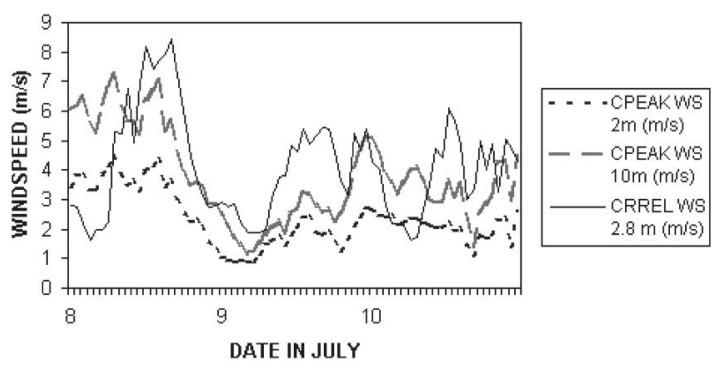

SURFACE STATION WIND DIRECTION
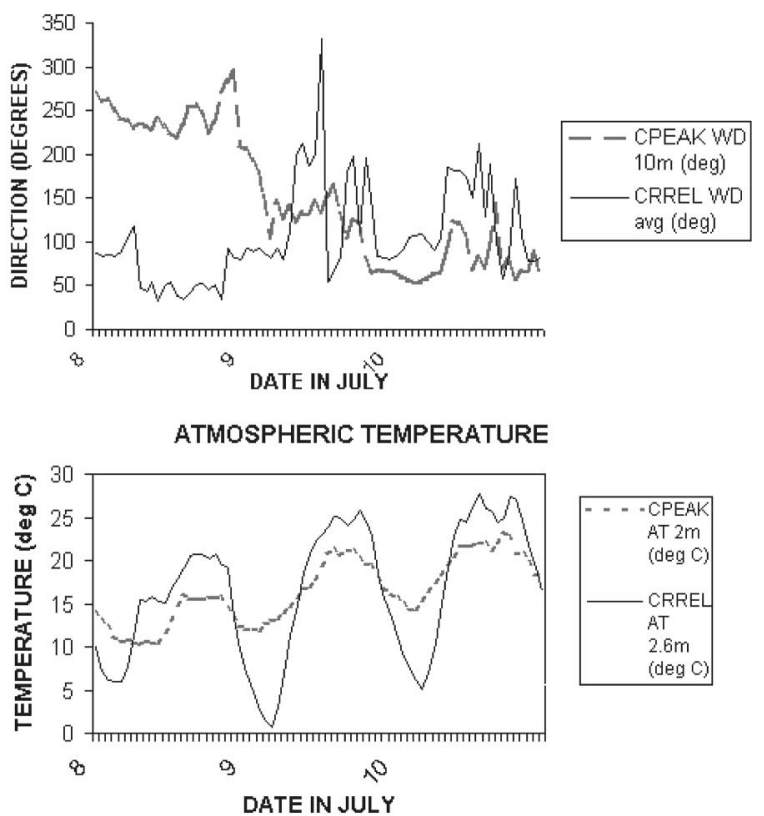

ATMOSPHERIC RELATIVE HUMIDITY

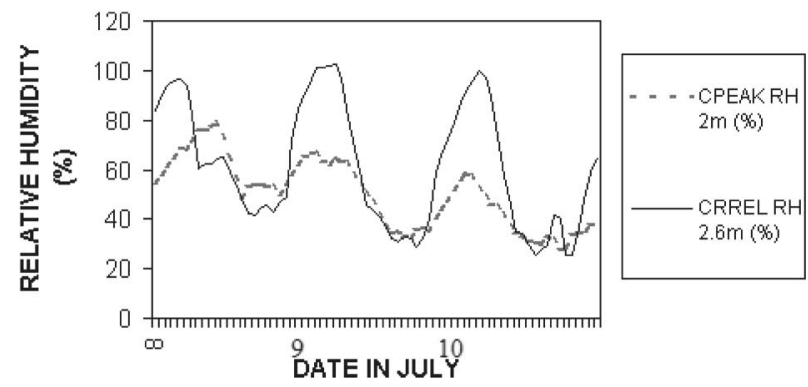

FIG. 3. Weather variables recorded at CPCRW stations CPEAK and CRREL. Legends contain the measurement height (data courtesy of Larry Hinzman and John Gallagher, University of Alaska, Fairbanks).

ning the smoldering fires in the lowest part of the valley, spreading these fires toward the top of Helmer's Ridge (see Fig. 4). Stands of black spruce flared up and fire spread rapidly upslope in running crown fires. At a position $2.6-3.2 \mathrm{~km}$ across the valley from the fire, data of several crown-fire periods of varying intensity ranging from smoldering fires to running crown fires were recorded on 9-10 July. Although the fires on 10 July were originally manually ignited, they were not guided by humans. Thus they evolved as natural fires. Burning continued throughout 10 July, with smoldering until 15 July when rains finally extinguished the fire. About $1 / 3$ of the possible acreage burned during FROSTFIRE, mostly in the black spruce-dominated areas, whereas the hardwoods (birch and aspen) and the wetter valley did not burn under these wind, humidity, and fuel moisture conditions (Hinzman et al. 2003).

\section{Instrument and data description}

\section{a. Instrument description}

Infrared imagers are one of the few instruments that can penetrate the smoke of fire to reveal motions within the flaming combustion zone and intense convective column with high temporal and spatial resolution. The instrument used for these observations is an Inframetrics, Inc., (now FLIR Systems, Inc.) ThermaCAM PM380: a digital, high-resolution infrared imager. The ThermaCAM incorporates a $256 \times 256$ element platinum silicide focal plane array recording over the 3.4$5.0-\mu \mathrm{m}$ wavelength range, which provides a sensing range between $-10^{\circ}$ and $1500^{\circ} \mathrm{C}$. Spectral filters extend the measurement range to accommodate high-temperature targets above $450^{\circ} \mathrm{C}$. The instrument has a 12-bit (4096 levels) measurement dynamic range over one of several temperature ranges selected by the user. The instrument's maximum sensitivity of $0.1^{\circ} \mathrm{C}$ can be achieved when the user sets a narrow temperature detection range. Instrument accuracy was specified to be $\pm 2^{\circ} \mathrm{C}$. A self-contained Sterling cooler is used to reach cryogenic temperatures (i.e., no external, bulky nitrogen cooling unit is required). Algorithms within the imager attempt to account for the gaseous medium between the subject and the imager. Although the imager had a $17^{\circ}$ $\times 16^{\circ}$ field of view, a $4^{\circ} \times 4.2^{\circ}$ telephoto lens was added, and so at a range of $2800 \mathrm{~m}$, for example, each reprocessed pixel ultimately represented an area of $0.376 \mathrm{~m} \times 0.845 \mathrm{~m}$. This model of the instrument does not have digital output but internally converts the 12bit digital data to an analog video signal. By detecting the radiant energy in this wavelength band and applying the user-set value of emissivity (an estimate, as discussed later), the imager estimates the radiating object's temperature and creates two-dimensional video images of hot, swirling air mixed with products of combustion in the fire, detailing their size, structure, and temperature.

\section{b. Data collection}

At a position approximately $200 \mathrm{~m}$ southwest of Caribou Peak, about 400-500 m above and 2.6-3.2 km across the valley from the fire, several crown-fire periods of varying intensity, ranging from smoldering fires to running crown fires, were recorded. Mounted on a 

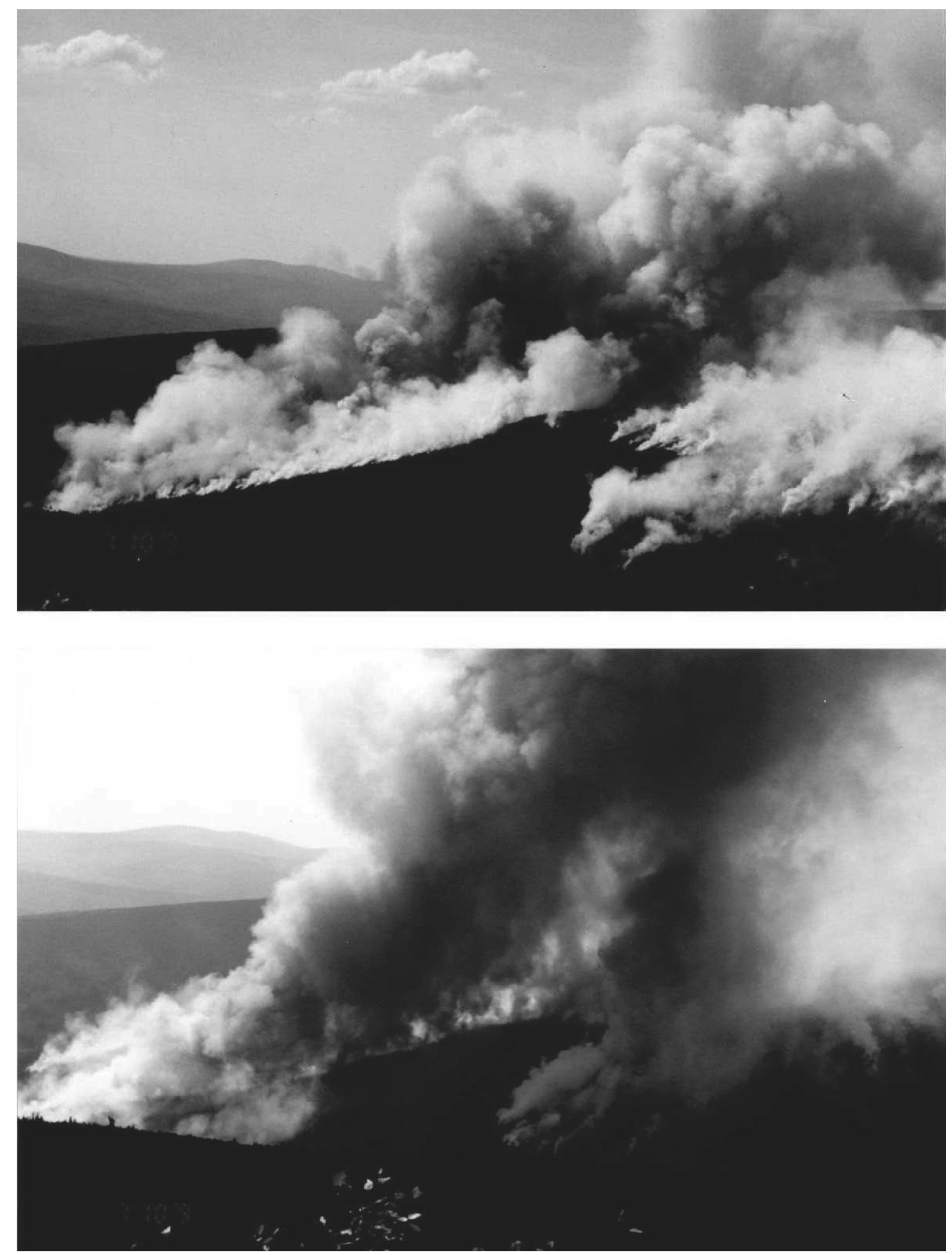

FIG. 4. Fire climbing ridge, viewed from Caribou Peak, at two times during sequence 5. East is to the left of the image, and west is to the right. 
TABLE 1. Imagery sequences.

\begin{tabular}{|c|c|c|c|c|}
\hline $\begin{array}{l}\text { Analyzed } \\
\text { sequence }\end{array}$ & $\begin{array}{l}\text { Distance } \\
\text { from } \\
\text { instrument } \\
(\mathrm{km})\end{array}$ & $\begin{array}{l}\text { Instrument } \\
\text { temperature } \\
\text { range }\left({ }^{\circ} \mathrm{C}\right)\end{array}$ & Local time and date & Subject \\
\hline 1 & 3.25 & $300-525$ & 1347-1349 LST 9 Jul & Blacklining \\
\hline 2 & 2.8 & $300-525$ & 1356-1359 LST 9 Jul & Blacklining \\
\hline 3 & 2.7 & $300-525$ & 2105:03-2106:50 LST 9 Jul & Ignition \\
\hline 4 & 2.75 & $300-525$ & 1140:46-1144:39 LST 10 Jul & Crown-fire run, viewed in profile \\
\hline 5 & 2.8 & $500-800$ & 1329:08-1330:07 LST 10 Jul & Crown-fire run, viewed in profile \\
\hline
\end{tabular}

tripod, the infrared imager had an unobstructed view of several fire sequences, either as fires climbed a ridge from left to right, giving an opportunity to study fire spread, or as fire climbed toward the peak traveling away from the observation station, giving a perspective along the width of the fire (see Fig. 2a and Table 1). For an overview of this and other radiometric instruments present at the Caribou Peak site, see Daily et al. (1999).

When collecting data, the user sets the target's emissivity, the distance to the target, and the atmospheric temperature and relative humidity. The user can select one of several temperature ranges on the imager and the span of temperatures within this range. The luminance measured by the camera (lumens) is converted by the instrument to temperature (degrees Celsius) using a fit to a factory-provided calibration curve [shown in Clark et al. (1999)]. When viewing fires, it is assumed that the targets are incandescent condensed particles of incomplete combustion (i.e., soot particles) in a shallow, warped, constantly changing image plane in the first few meters of depth of the combustion zone and that the gas phase is effectively transparent. If the flame is thick $(>1 \mathrm{~m})$ and luminous, it is common to assume essentially blackbody (emissivity $\sim 1$ ) behavior (Drysdale 1998); thus, the emissivity was set to 0.95 . Variation in emissivity over the target area captured in the image is neglected. Although the target's true emissivity can only be estimated, an error in estimating this parameter affects the measured temperature slightly but not the winds inferred from these data (which are based upon gradients of this property) and, therefore, not the conclusions based on the analysis.

The $60-\mathrm{Hz}$ analog black-and-white video signal from the infrared imager is recorded to a standard VHS videocassette recorder at 30 frames per second, although these data are later temporally split (see section $3 \mathrm{c}$ ) to produce 60 frames per second. Although a higher-resolution SVHS recorder is now used, the authors do not know of currently available portable recording devices that can further improve this step of the process for this instrument.

\section{c. Data preprocessing}

This analog imagery is digitized and recorded as eight-bit (256 levels) uncompressed digital data on an
Accom, Inc., 2Xtreme CCIR601 videodisc array and are deinterlaced based on some simple assumptions, giving effectively 60 frames of data per second. Interlaced video signals consist of two video fields, each containing the odd or even lines of the image. During the imagecapture process, cameras output the odd lines at one time and then, $33 \mathrm{~ms}$ later, output the even lines, which are combined into one image. This procedure creates a temporal shift between the odd and even lines that must be addressed for data analysis of rapidly changing fields. For data analysis, the images are deinterlaced to their original state; that is, odd and even horizontal lines are split into two temporally aligned files $(720 \times 243$ pixels $)$ that are assumed to be separated by a time interval of 1/60th of a second. Assumptions are that the image subject has not changed substantially in the 1/60th of a second required to capture the image and that the image height represented by the vertical pixel height of each scanned line can be doubled (because every other line has been removed) to reconstitute the image's original dimension. These Quantel, Inc., National Television System Committee (NTSC) images (a professional digital video standard with nonsquare pixels) are resampled to convert to an image with square pixels [red-greenblue (RGB) format], and the images' luminance field is converted to readable 1-byte binary files that are then analyzed.

Although this instrument (Inframetrics PM-380) does not have digital output, other versions (such as the SC1000, with 12-bit serial digital output) do; data from them could be recorded directly in digital format, eliminating some of this process. At this time, however, most digital recording devices limit the immense volume of data by relying on compression schemes that lose data quality; these schemes are not suitable because of the errors introduced into the data. Other digital recording devices that circumvent this compression method by limiting the data flow with lower frame rates are also undesirable because they decrease the data's temporal resolution. We continue to seek to improve this process but are limited until a similar instrument with digital output can be recorded on a portable digital recorder with no compression.

The data produced by the infrared imager are the temperature of the graybody in the image plane. To extract more information beyond the evolution of tem- 
perature, one must make further assumptions and apply analysis algorithms, described next.

\section{d. Image-flow analysis}

Gradient-based image-flow-analysis methods were used to extract fire wind estimates from the temporal and spatial evolution of the temperature field. These techniques are a variant of Verri et al. (1990), incorporating details described in detail in Clark et al. (1999). The broad purposes of this analysis technique are to calculate combustion-zone winds and fire spread rates, to study crown-fire dynamics, and to derive statistics of fire winds (magnitude, and temporal and spatial scales of motions) that can be used to understand crown-fire dynamics, to assess modeling requirements, and to validate coupled atmosphere-fire models (Clark et al. 1996a,b, 2004; Linn et al. 2002). Other techniques that are likely to produce better accuracy have been benchmarked (Bab-Hadiashar and Suter 1998; Farnebäck 2001, 2002; Wang and Suter 2003).

These methods have two steps. The first step is image registration, which includes extracting motions of the observation platform (such as the swaying of a tower; aircraft roll, yaw, and pitch changes; wind buffeting; and deliberate movement of the camera), if any (none was required for these observations), and georeferencing the images; the second step is image-flow analysis, which involves describing the motion in the image plane as a composite of the five elementary motions from Helmholtz's theorem for deformable objects. These motions include two components of translation, rotation, expansion, and two orthogonal components of shear, but, as in the Clark et al. (1999) procedure, only the two translation components are considered so as to limit the complexity. The governing equation for image flow is

$$
\frac{d f}{d t}=f_{t}+u f_{x}+w f_{z},
$$

where $f$ represents the measured temperature, $u$ and $w$ are the horizontal ( $x$ direction) and vertical ( $z$ direction) components of the wind velocity, time is indicated by $t$, and the subscripts indicate first-order partial differentiation with respect to the subscript variable. Basic assumptions in this method are that 1) $f$ is approximately conserved (i.e., local features can be followed) for short periods (i.e., about seven frames, or $0.1 \mathrm{~s}$ ), 2) the combustion zone has high emissivity $(\sim 1.0), 3)$ the infrared imager detects incandescent condensed soot particles that trace the air motion, 4) the motion is on a distorted two-dimensional surface, and 5) the data can be fit to simple kinds of motions such as translation.

Taking the gradient of (1) gives the following matrix equation:

$$
\left(\begin{array}{ll}
f_{x x} & f_{x z} \\
f_{x z} & f_{z z}
\end{array}\right)\left(\begin{array}{c}
u \\
w
\end{array}\right)=\left(\begin{array}{l}
-f_{t x} \\
-f_{t z}
\end{array}\right),
$$

the determinant det of which is

$$
\operatorname{det}=f_{x x} f_{z z}-f_{x z}^{2} .
$$

If $|\operatorname{det}|$ is relatively large, that is, there is sufficient structure to the flow, then solutions for $u$ and $w$ can be found. Details of the solution of (3) can be found in Clark et al. (1999). In summary, (3) is solved using a least squares method in which transformations (such as our two-component translation, but which more generally would also include rotation and stretching) are given polynomial fits. A temperature threshold of $40^{\circ} \mathrm{C}$ over the lowest temperature of the selected temperature range was chosen subjectively to eliminate the small, random noise introduced during calculations (primarily through algebra of calculated gradients over small differences). One difference from Clark et al. (1999) is that local minimizations are performed over local patches of data $(7 \times 7$ pixels $)$ around each pixel instead of over the entire field.

\section{Results}

Five periods of crown-fire propagation during 9-10 July 1999 (listed in Table 1) are analyzed. These range in duration from 1 to $5 \mathrm{~min}$; data recording was broken off either because the fire subsided or because it traveled across the field of view and exited, requiring that the imager be reaimed. Nevertheless, even the 1-min sequences are long enough to capture representative behavior that reveals dynamics within the fires. The orientation of the imager with respect to the fires is important - the geometry on sequence 5 is unique and ideal: the forward spread was across our two-dimensional cross section. In other sequences, the fire was directly ahead (sequence 1), traveling away from us, or at some angle up the hill (sequence 2), making interpretation of the three-dimensional motions more ambiguous.

\section{a. Sample sequence of images}

Figure 5 shows temperature images from sequence 5 (temperature range $500^{\circ}-800^{\circ} \mathrm{C} ; 2.8 \mathrm{~km}$ away from imager). With $520 \times 243$ eight-bit (256 level) data pixels in the reprocessed image, each pixel represents an area with dimensions $0.376 \mathrm{~m} \times 0.845 \mathrm{~m}$ with temperature increments of $1.17^{\circ} \mathrm{C}$, providing exceptional resolution for analyzing the motions within the flaming combustion zone. The high temporal resolution of the data is necessary, because significant changes in the images occur within a fraction of a second.

The high-temperature regions identify the flaming combustion of an envelope of volatile gases released by pyrolyzing surface fuel and individual trees. These gases are not instantly consumed, and pockets may be transported some distance before entrainment with environmental air produces the stoichiometric conditions needed for combustion. Although one must be cautious in interpreting the temperature data because of the assumptions made about emissivity, the temperatures are 

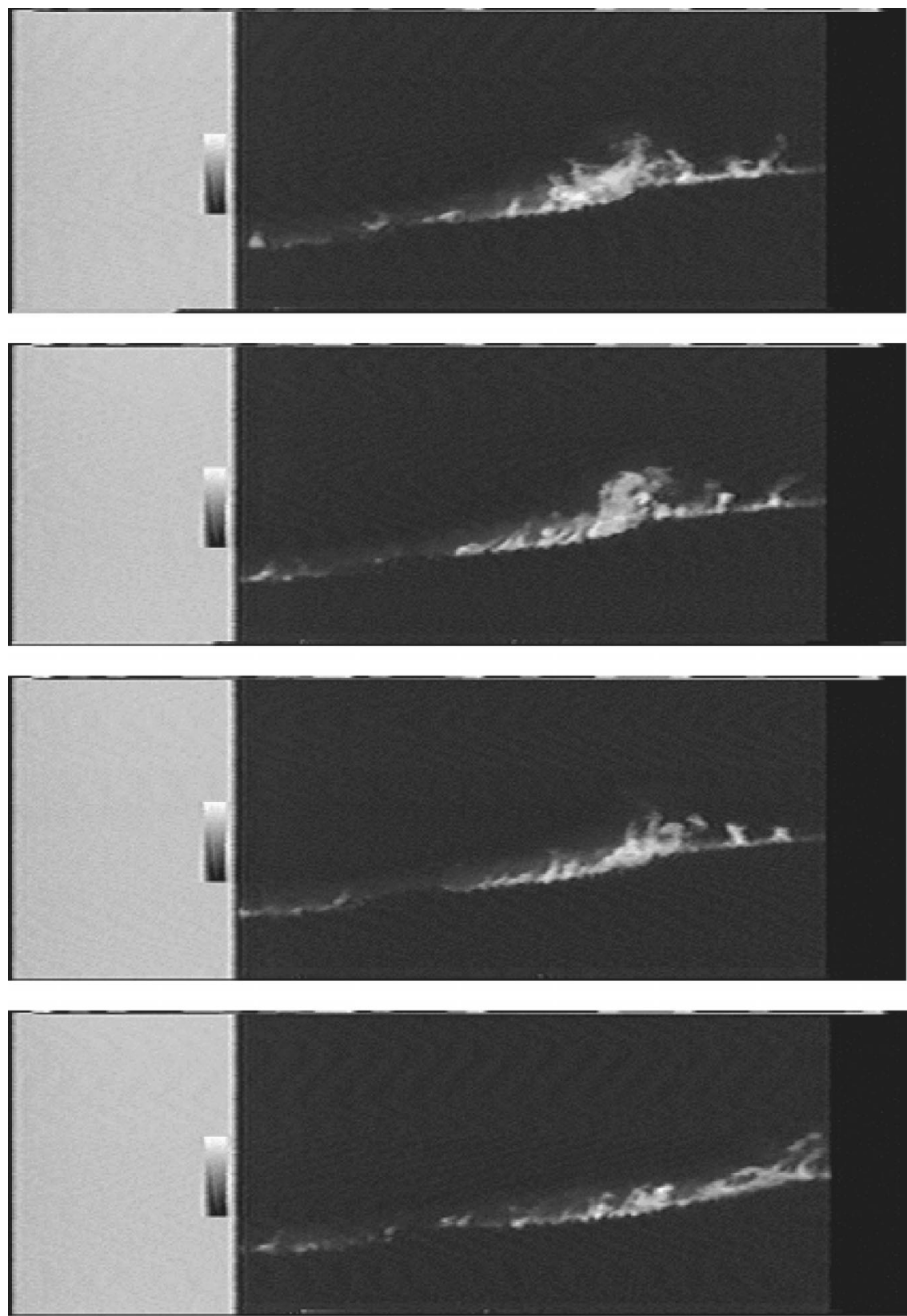

FIG. 5. Temperature images at six times relative to the beginning of sequence 5: $1.85,4.00$, 9.77, and $41.37 \mathrm{~s}$, from top to bottom. The grayscale image data correspond to temperatures of the range $500^{\circ}$ (black) $-800^{\circ} \mathrm{C}$ (white), as shown in the temperature scale to the left of each image The fire is traveling from left to right. Because of deinterlacing, the vertical scale is compressed; the image area is $195 \mathrm{~m} \times 205 \mathrm{~m}$.

well within the range expected for combustion in diffusion flames. The imager detects infrared radiation from intermediate combustion particles and particles of incomplete combustion (such as soot) until they mix and cool enough to be outside the selected detection temperature range. The outline of treetops (dark, cool region) can be discerned at the base of the flaming combustion, although individual trees are spaced slightly closer than the resolution can show. This outline of tree- tops, calculated as the highest vertical point at which the temperature is not raised over ambient, was followed over time to identify the ridgeline in the infrared data. The terrain slope was approximately $20^{\circ}$ and is used in later sections to calculate the velocities parallel to the surface.

The images show a crown fire traveling upslope from left to right. Some features are apparent. Although the crown fire is pyrolyzing and igniting the gases from 
individual trees, the convective heat from several trees rapidly loses the scale of individual trees (approximately 1-5 $\mathrm{m}$ apart) and agglomerates into many larger-thanindividual-tree-scale convective plumes. Although buoyant, these elements do not simply rise vertically, but shoot some distance parallel to the slope before buoyancy forces take over and the plume rises much more vertically, tilted in the downwind direction (here, left to right). The fire's spread upslope is not smooth but is characterized by a sequence of these bursts of flame. A more quantitative analysis of these motions is presented in sections $4 \mathrm{~b}$ and $4 \mathrm{c}$.

\section{b. Velocities}

The air velocities in and near the fire cannot be regarded as an external force directing the fire, but are themselves partly driven by the fire and are an intrinsic part of the dynamics of fire propagation. For example, the vertical velocity and its vertical gradient influence the surface convergence pattern and, thus, the smallscale fire-induced winds that drive the fire. Vertical velocities are important both as an indication of the fire's intensity and because they are used to calculate the fluxes and transport of sensible heat and emissions. They also influence how high and, therefore, how far spotting embers are lofted. The image-flow analysis technique described in section $3 \mathrm{~d}$ was used to analyze the sequence of temperature data and to determine atmospheric motions in and around the fire. Both Cartesian velocities and velocities that are parallel and normal to the slope will be presented.

Figure 6 shows the air velocities at the same times as the IR grayscale data images of Fig. 5. A 1-2-1 spatial filter has been applied to the data, and a threshold of $40^{\circ} \mathrm{C}$ over the bottom of the temperature range (i.e., all temperatures below this value were set to the threshold) was used in the velocity calculations to eliminate the erroneously large, noisy velocities that would be calculated away from the main features where there is a relatively weak feature amid the noise.

Under a weak westerly upslope wind that is partially ambient and probably modified by the fire itself because of the strong forcing nearby, the plumes do not immediately rise vertically, but shoot tens of meters parallel to the slope before buoyancy forces take over, after which time the plumes rise more vertically. Although this analysis readily reveals the updrafts created by the fire, it captures only some of the necessary downward transport of air into the rear of the updraft base. When it does so, this air must already contain warm, radiating particles from the fire in order to be detected by the imager-transport of clear air is not detected.

More physically relevant than the horizontal wind component is the wind component along the slope. This component was obtained by calculating the dot product of the total wind vector with the gradient slope, which in sequence 5 is $20^{\circ}$. Although the strongest atmospheric winds overall are located in the rising convective plume several tens of meters above the ground, Fig. 7 shows how close the forward bursts described earlier are to the ground. In this sequence, velocity components parallel to the surface of $10 \mathrm{~m} \mathrm{~s}^{-1}$ are routine, with frequent bursts of $25 \mathrm{~m} \mathrm{~s}^{-1}$. Peak surges of $30 \mathrm{~m} \mathrm{~s}^{-1}$ are detectable less than $15 \mathrm{~m}$ above the base of the detectable fire.

The analysis cannot precisely identify how deep into the trees and close to the ground these forward-bursting fingers penetrate because intervening treetops partially obscure the view, nor can the analysis show how flow is modified and mitigated by canopy drag. However, it is clear that for some distance these flame-filled fingers are traveling parallel to the ground at heights at which they can propagate the fire by igniting through contact as well as preheating and drying the canopy ahead of the fire, making it easier to ignite. The speed the fingers travel parallel to the slope is an order of magnitude larger than ambient winds measured by nearby surface weather stations, and the motions are far more complex than tilting of a buoyant updraft. These observations suggest that nonlinear interactions are at the heart of propagation in crown fires and transfer some of the vertical momentum created by buoyancy into bursts primarily traveling along the surface before buoyancy forces take over and produce a mostly vertical plume rise.

\section{c. Statistical maxima}

It can be shown under very general assumptions that the distribution of independent random errors of observation takes on a normal distribution as the number of observations becomes large. A classical normal ("Gaussian") distribution is assumed to represent the distribution of observed values. If the Gaussian distribution were accurate, the probability that the extrema deviate from the mean by more than 5 standard deviations would be $0.00003 \%$. Figure 8 shows the windvelocity-component imagewide maxima statistics over sequence 5. Thin lines show the actual maxima of the vertical velocity component (Fig. 8a), and thick lines in each plot represent the mean \pm 5 standard deviations, which should represent the extrema values in a Gaussian-distributed dataset. Under this assumption, when maxima values fall outside this range, one can assume they are artificially produced outliers overlooked by the analysis scheme. These statistical extrema may be more physically meaningful estimates of maximum velocities.

The vertical velocity statistics show that, even in the more conservative statistical estimates, maximum updrafts of over $60 \mathrm{~m} \mathrm{~s}^{-1}$ are common in this and the other sequences. The negative vertical velocities in Fig. 8a reflect the downdrafts bringing air into the fire-here consistently reaching peaks over $20 \mathrm{~m} \mathrm{~s}^{-1}$, a value that is substantially smaller than the peak updrafts. The positive (updraft) maxima showed a pulsing behavior with an almost periodic nature, with distinct peak updrafts 
TEMPERATURE ( deg $C$ )
TIME $=1.833 \mathrm{gec}$

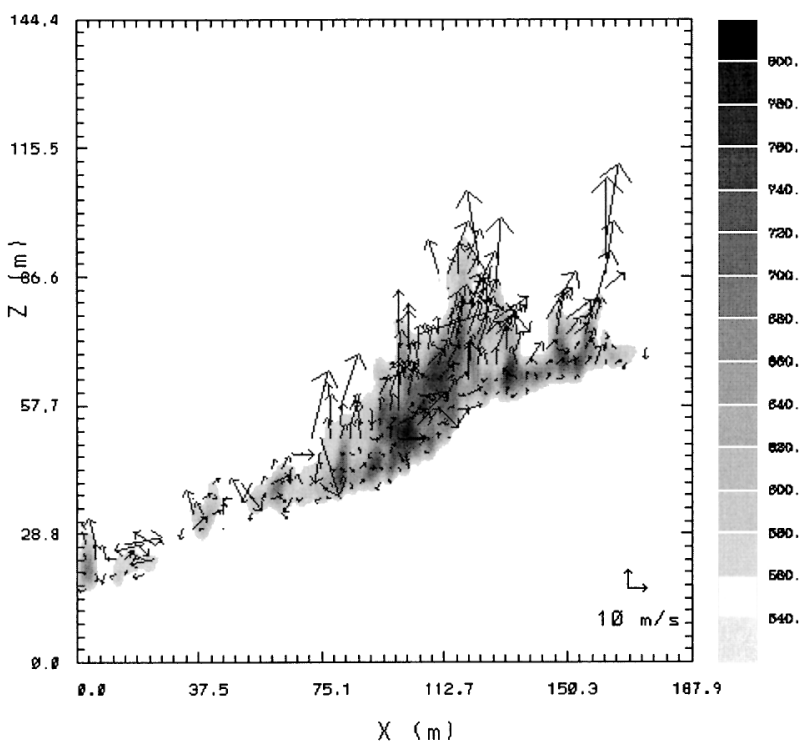

TEMPERATURE (deg $C$ )
TIME $=9.083 \mathrm{sec}$

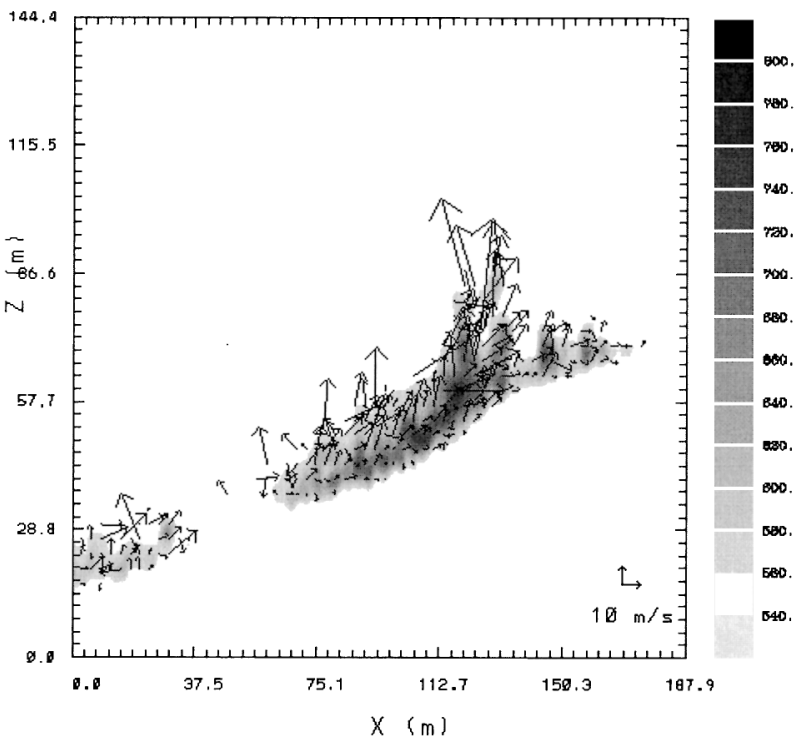

TEMPERATURE $(\mathrm{deg} C)$
TIME $=4.083 \mathrm{gec}$

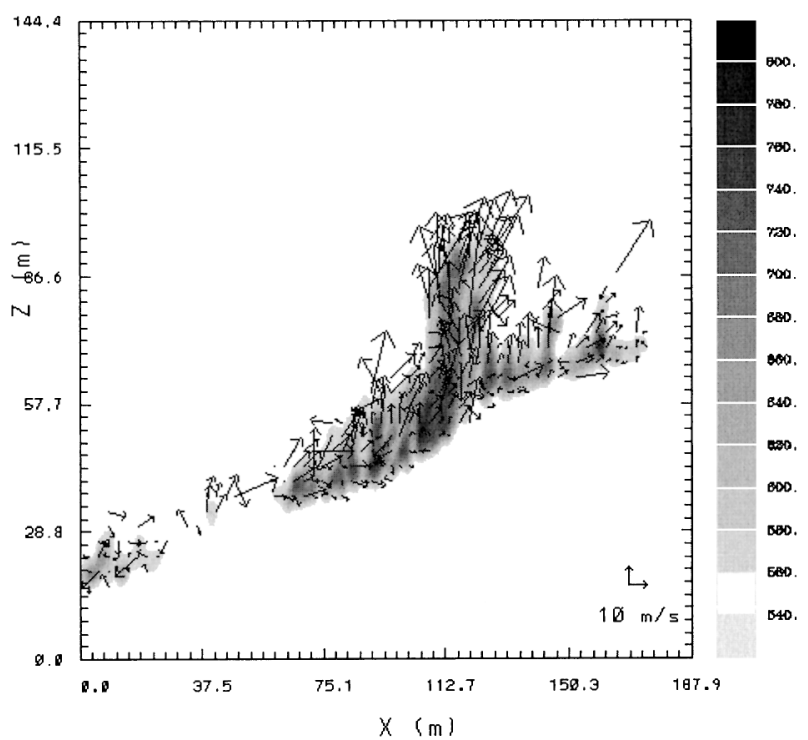

TEMPERATURE $(\mathrm{deg} C)$
TIME $=41.40 \emptyset \mathrm{gec}$

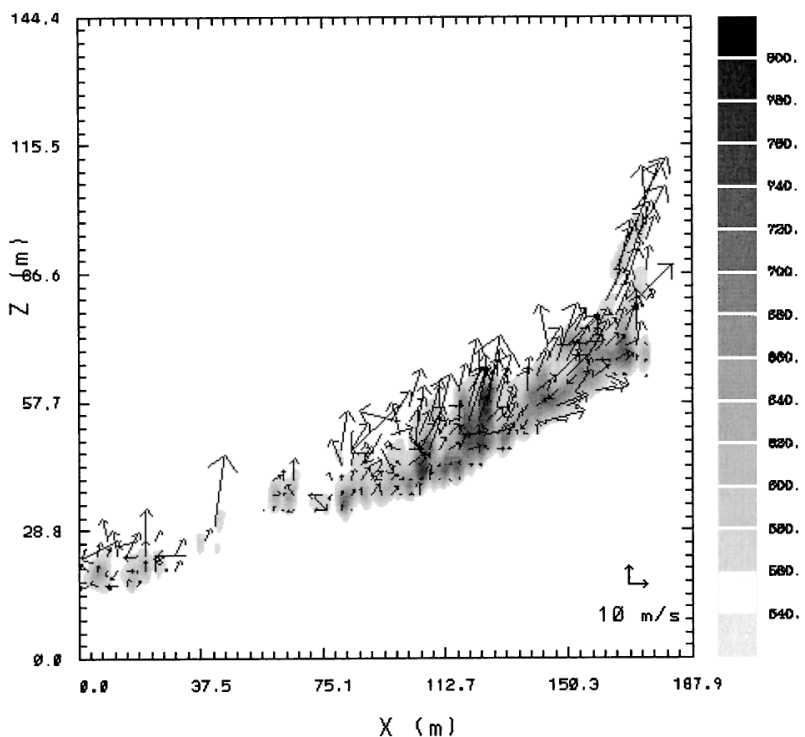

FIG. 6. Sequence of images obtained from image-flow analysis (with calculated vectors) during sequence 5 . This image corresponds to the dark line in Fig. 2a. (East is to the left.) Shaded contours show the temperature detected by the infrared imager. The vectors show the calculated flow velocities. Every eighth point in the $x$ direction and every fourth point in the $z$ direction are plotted.

occurring approximately every $1.8 \mathrm{~s}$ for the first $50 \mathrm{~s}$ (3000 frames). This pulsing is also not apparent in the downdraft maxima, presumably because the downdraft maxima location varies much more and is not tied to individual surges. The horizontal wind maximum (not shown) is steadier-the statistically estimated maximum wind speed (at 5 std dev greater than the average) is 22-24 $\mathrm{m} \mathrm{s}^{-1}$ throughout the sequence.

The component of the wind parallel to the slope shown in Fig. 8b shows the time history of the maximum of this quantity throughout the domain (thin lines), as well as the statistical estimate of the maximum calculated the same way as was discussed in previous paragraphs. In this fire, this component frequently has peaks of $35-40 \mathrm{~m} \mathrm{~s}^{-1}$, with some evidence of pulses in the maximum value with time; however, the amplitude of the peaks over the values in between peaks is less exaggerated than in the vertical velocity. Figure $8 \mathrm{c}$ shows that the maximum velocity magnitude ranges from 32 to $60 \mathrm{~m} \mathrm{~s}^{-1}$. The peak speeds are reached in 

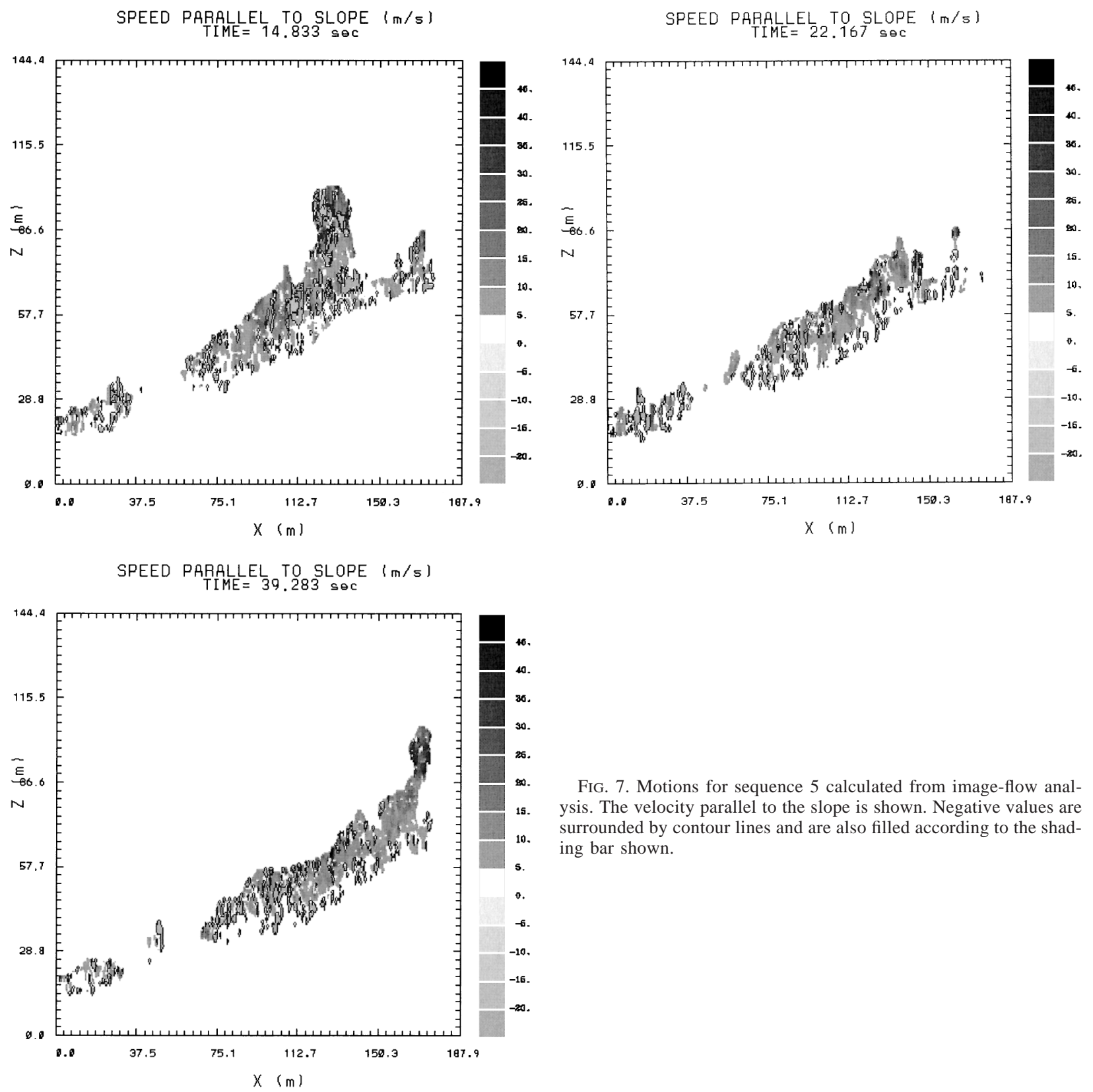

Fig. 7. Motions for sequence 5 calculated from image-flow analysis. The velocity parallel to the slope is shown. Negative values are surrounded by contour lines and are also filled according to the shading bar shown.

the highest detectable heights of the most dominant updrafts in the image, after heat from individual trees has combined to form an accelerating convective plume.

\section{d. Profiles}

To summarize the fire's overall effect on the atmosphere, vertical profiles of fields averaged over the domain as a function of time are presented. Ground level is identified as the lowest point in each column that ever experiences a perturbation in temperature above the background field. These profiles allow us to assess the fire's vertical structure and to estimate the height to which it influences the local energetics of the atmosphere.

The profile of vertical velocity for sequence 5 averaged over the domain's width (Fig. 9a) shows that the fire affects the air in its vicinity with an average updraft of at least $0.25 \mathrm{~m} \mathrm{~s}^{-1}$ for at least $50 \mathrm{~m}$ above the fire. The peak updraft is not at the height of the fuel but is at $20-25 \mathrm{~m}$ above it, after the individual plumes have merged and accelerated. Near the surface, on average over the image width, the vertical velocity is from -0.25 to $-0.5 \mathrm{~m} \mathrm{~s}^{-1}$, reflecting the recirculation of fire-modified air into the base of the updrafts. These values could be an underestimate, because this 
(a) PFiofil Y STATISTISS

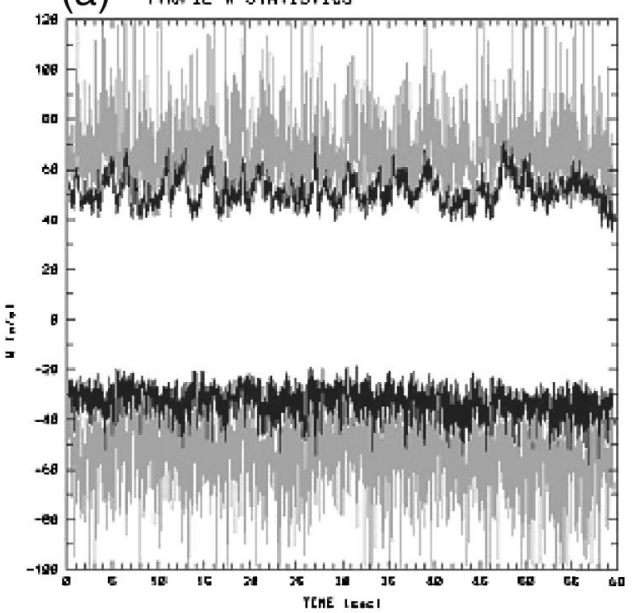

(b) FAOF IL SFu Fah STRTIStics

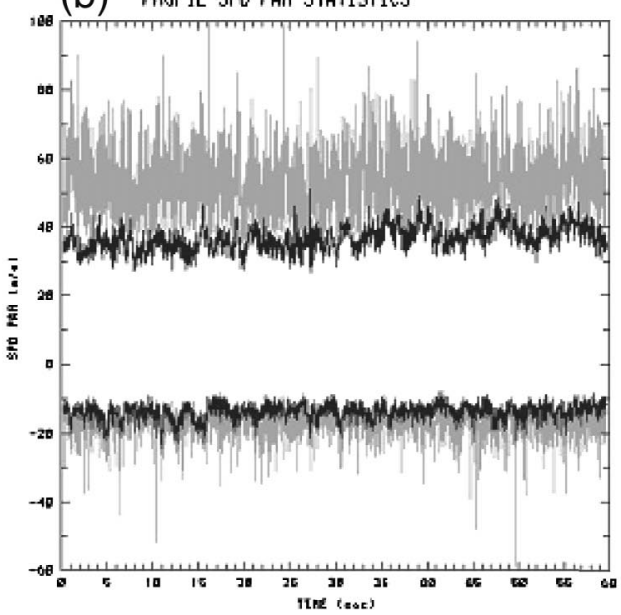

(c) PROFIL SPD MAG STATISTICS

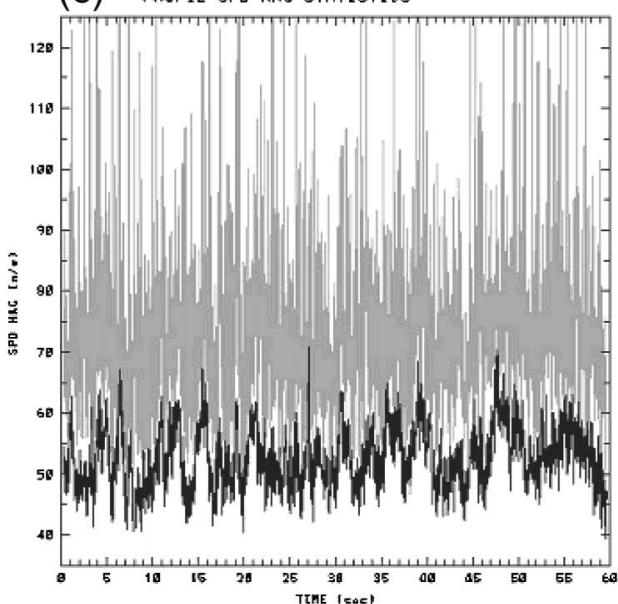

FIG. 8. Velocity statistics for domainwide maximum and minimum for sequence 5: (a) $w$ (vertical velocity) component, (b) extrema for the (derived) velocity component parallel to the slope, and (c) the maximum air speed. Actual calculated maximum values are shown in gray; black lines show expected extrema that are $\pm 5 \mathrm{std}$ dev from the imagewide mean statistical values. detection method misses clear-air downdrafts. During the last third of the sequence, the fire's right flank (the side facing the imager) makes a run along the ridgeline that causes the height of peak velocities to drop.

The temperature perturbation revealed by the imager (Fig. 9b) extends up to approximately $50 \mathrm{~m}$ above the base of the fire. Few individual or agglomerated convective plumes extend above this height, either because they have entrained enough air to dilute below the sensible temperature threshold or, more likely, because the air parcels have radiatively cooled below the fixed temperature range $\left(500^{\circ}-800^{\circ} \mathrm{C}\right)$. Although temperature perturbations below $500^{\circ} \mathrm{C}$ still contribute to the heat flux and are not included in these numbers, analysis of other sequences in lower temperature ranges showed they are limited to a small region around the fire and contribute a small amount of heat relative to that detected in the $500^{\circ}-800^{\circ} \mathrm{C}$ range.

Wildfires release extreme amounts of sensible heat, with values orders of magnitude larger than other atmospheric sources such as solar heating. Even though their areal extent is limited, wildfires can substantially alter local atmospheric dynamics and thermodynamic structure and alter flow through scale interactions. The profile of the sensible heat flux $H_{s}$ was calculated as

$$
H_{s}=\rho c_{p} w^{\prime} T^{\prime},
$$

where $c_{p}$ is the specific heat of dry air at constant pressure, $T^{\prime}$ is the measured temperature perturbation, $w^{\prime}$ is the vertical velocity perturbation calculated using image-flow analysis, and $\rho$ is density, calculated locally using

$$
\rho=\frac{p}{R_{d} T_{v}},
$$

where $p$ is pressure, $R_{d}$ is the gas constant, and $T_{v}$ is the virtual temperature. Both $c_{p}$ and $\rho$ are functions of temperature and the chemical composition of the air. Here we have assumed in (5) that the pressure perturbations and water vapor contributions to the variability of density can be neglected (introducing small errors to our results), that the vertical motions outside our detected region are negligible, that air is prevalent in excess, that the variation in $c_{p}$ over this temperature range is negligible, and that the image suitably frames the region of interest but is not so large as to dilute our spatial averages. Because $H_{s}$ varies greatly in time and space and is primarily used to represent the flux contributed over the fire area, the horizontally averaged vertical profile of $H_{s}$ as a function of time is presented (Fig. 9c). It is estimated from the imagery that the imager receives radiant energy halfway into the depth of the 10-m trees, thus, the base of our measurements is approximately $5 \mathrm{~m}$ above ground level. The horizontally averaged peak sensible heat flux is $0.3-1.2$ 
(a) VERT PROFILE YERTICAL VELOCITY $\{\mathrm{m} / \mathrm{s}$ )

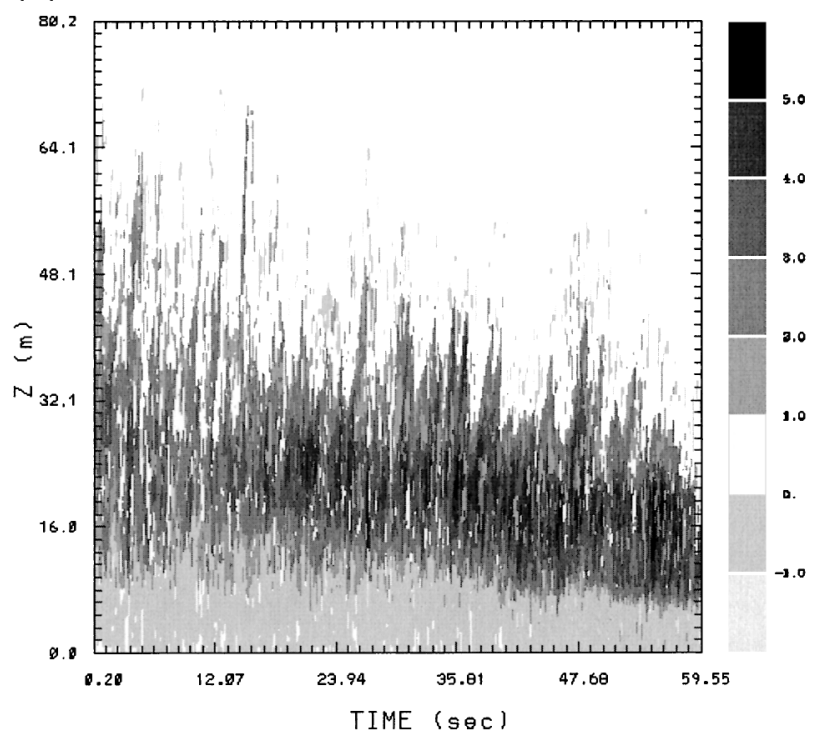

(c) VERT PROFILE SENSIBLE HEAT (MW/m²)

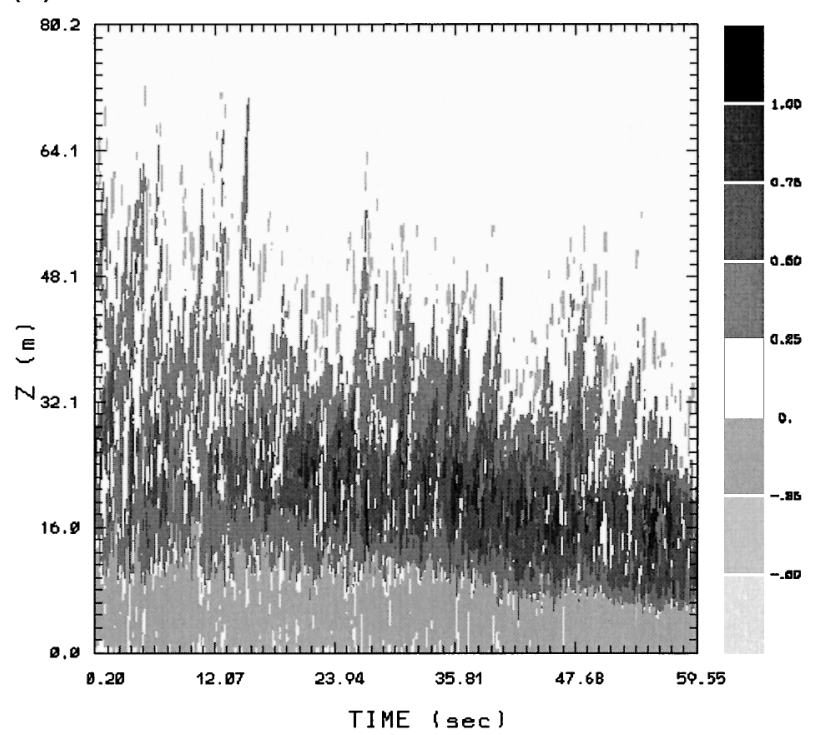

(b) VERTICAL PROFILE TEMPERATURE (deg $\mathrm{C}$ )

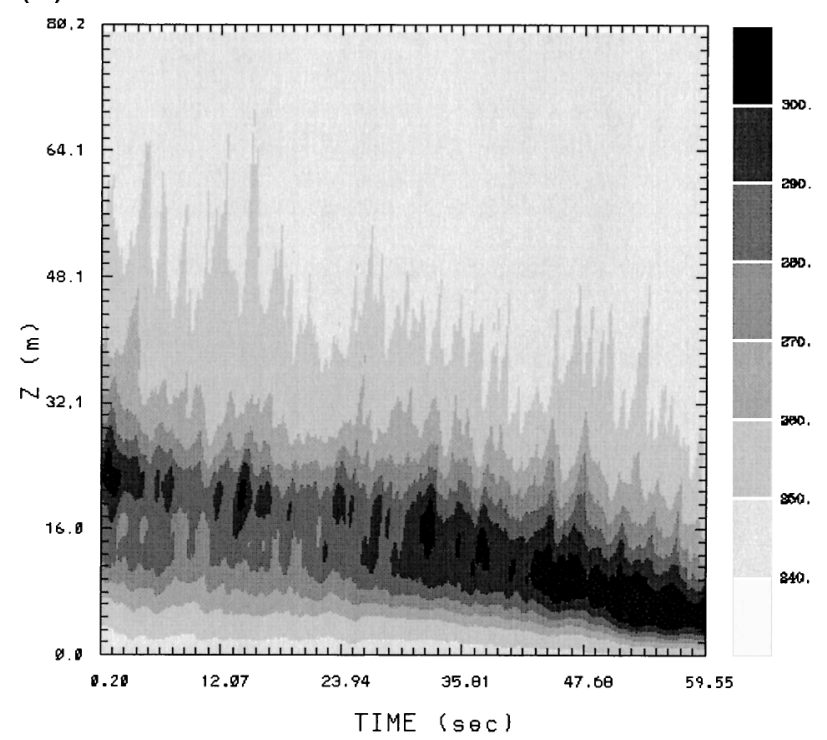

(d) VERTICAL PROFILE HIND SPEED $\{\mathrm{m} / \mathrm{s}$ )

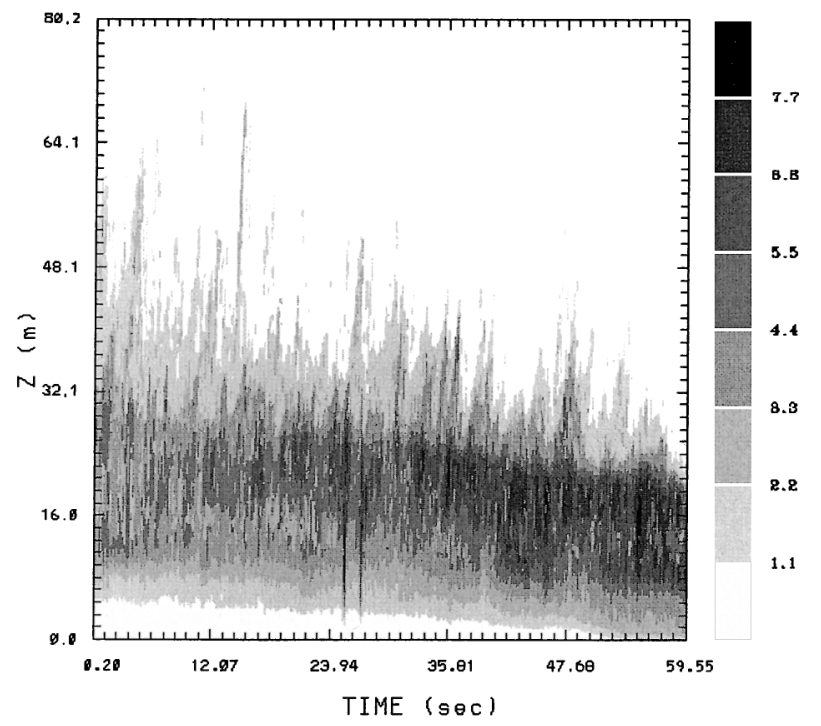

FIG. 9. Average vertical profiles (averages taken at constant height above ground level) of (a) vertical velocity ( $\mathrm{m} \mathrm{s}^{-1}$ ), (b) temperature perturbation from ambient $\left({ }^{\circ} \mathrm{C}\right)$, (c) sensible heat flux $\left(\mathrm{MW} \mathrm{m}^{-2}\right)$, and (d) speed $\left(\mathrm{m} \mathrm{s}^{-1}\right)$ for sequence 5 .

MW $\mathrm{m}^{-2}$, located $21-25 \mathrm{~m}$ above ground, although maximum sensible heat fluxes of 7-11 $\mathrm{MW} \mathrm{m}^{-2}$ (with statistical outliers removed using the techniques in section 4c) are found. Smaller negative values of $H_{s}$ near the ground reflect downdrafts recirculating warm air recently passed through the fire (because the particles in it are still hot and radiating) into the base of convective updrafts. Although this method readily calculates the positive sensible heat flux associated with the upward transport of relatively warm air, it does not account for all of the downward transport of relatively cool air (also a positive contribution to sensible heat flux), because it is likely that some of the air brought down into the base of the fire updraft is clear air that contains no glowing soot particles to be captured by the imager or is air that has cooled outside the prescribed temperature range.

The wind speed magnitude averaged over the domain (Fig. 9d) increases throughout the sequence to a peak of $6 \mathrm{~m} \mathrm{~s}^{-1}$ at a height of $15-20 \mathrm{~m}$ above the bottom of the imaged region (approximately $20-25 \mathrm{~m}$ above ground). The height at which this average approaches 0 is about $50 \mathrm{~m}$, suggesting that the kinetic energy of this fire, on average, is contained and released into the atmosphere within this depth, defining a unique zone strongly affected by the fire. 


\section{e. Spread rates}

One of the most important aspects of fire behavior is the spread rate-the speed at which the interface between burning and nonburning fuel progresses in a direction normal to the interface. It is difficult to calculate an overall canopy spread rate for this fire because, rather than a smoothly spreading interface, the observations show repeated flame-filled bursts from the fire's core upslope along the treetops. (These ignited patches of treetop ahead of the main fire flared up in intensity as the most dynamically active core of the fire approached.) However, our perspective allowed the calculation of the spread rate in a fire flank oriented toward the imager that surged toward the right of the imagery during this period. This was done by calculating the progression of the leading edge of the $540^{\circ} \mathrm{C}$ isotherm in our imagery. During $50 \mathrm{~s}$ of sequence 5 , this front traveled $43 \mathrm{~m}$ upslope, giving this feature an average spread rate of $0.75 \mathrm{~m} \mathrm{~s}^{-1}$. The latter half of this period was more active, with an average spread rate of $1.11 \mathrm{~m} \mathrm{~s}^{-1}(2.48$ $\left.\mathrm{mi} \mathrm{h}^{-1}\right)$. The maximum over any 10 -s period was 1.26 $\mathrm{m} \mathrm{s}^{-1}\left(2.82 \mathrm{mi} \mathrm{h}^{-1}\right)$. Although crown fires may travel at a wide range of speeds, these spread rates are substantial, especially considering the comparatively light environmental winds.

\section{f. Other sequences}

Further examples of bursts of flaming fingers in sequences 3 and 2 are shown in Figs. 10 and 11, respectively. In sequence 3 , the fire is traveling upslope (into the image toward the upper right) with the well-known universal fire shape, with one very active updraft area at the head (Fig. 10a) sustained by heat brought forward by winds parallel to the flanks. The head intensifies as pockets of air with temperatures of over $500^{\circ} \mathrm{C}$ are drawn into it and stretched, and a narrow ( $5 \mathrm{~m}$ wide) finger of flame shoots $25 \mathrm{~m}$ upslope (Fig. 10b) before turning vertically upward, as shown by the derived velocities (Fig. 10c). The convective finger breaks off (Fig. 10d) into a hot rising thermal before the 1-2-s cycle repeats.

Although sequence 2 exemplifies this same flamingfinger behavior, it manifests in a row of updrafts (a consequence of a line heat source breaking up into convective cells) spread across a broad, wide fire line (a dynamic consequence of a less steep slope, slower winds, weaker updrafts, or less rapid burning), and thus displays a slower spread rate (Coen et al. 2001). In between the updrafts, $10-27 \mathrm{~m} \mathrm{~s}^{-1}$ downdrafts supply air into the base of the updrafts. A finger on the right side is beginning (Figs. 11a and 11b) as a finger on the left side is breaking off into a thermal.

\section{Discussion}

These observations and analyses present a unique (high spatial and temporal resolution) perspective into the motions within a crown fire propagating up a forested slope in interior Alaska. The overall picture that emerges from these results is dynamically complex and defies the common notion of one large convective plume or many tree-scale plumes that rise separately, simply accelerating under the force of buoyancy. Instead, the picture that emerges is a sequence of surges of many convective plumes that represent a scale larger than individual trees. These upslope bursts of flame initially have a strong along-ground component that in this situation exceeds ambient environmental winds (the winds generally considered to be "driving" the fire) by a factor of 10 . These bursts play an active role in propagating the crown fire and point toward a powerful, dynamic mechanism of fire spread. These observations revealed motions within a crown fire with conservative estimates of maximum updrafts of 32-60 $\mathrm{m} \mathrm{s}^{-1}$, maximum downdrafts of $18-30 \mathrm{~m} \mathrm{~s}^{-1}$, maximum horizontal wind speeds of $12-28 \mathrm{~m} \mathrm{~s}^{-1}$, and maximum winds parallel to the slope of 28-48 $\mathrm{m} \mathrm{s}^{-1}$. Average spread rates for a flank of the fire were $0.75-1.11 \mathrm{~m} \mathrm{~s}^{-1}$, and the peak spread rate over any 10 -s period was $1.26 \mathrm{~m} \mathrm{~s}^{-1}$. These values exceed the Clark et al. (1999) estimates of updrafts of between 10 and $30 \mathrm{~m} \mathrm{~s}^{-1}$, downdrafts of $10-20 \mathrm{~m} \mathrm{~s}^{-1}$, and horizontal flows of $5-15 \mathrm{~m} \mathrm{~s}^{-1}$ found in a prescribed crown fire in boreal forest in the International Crown Fire Modeling Experiment; however, there the fire was still accelerating from its average spread rate of 0.6 $\mathrm{m} \mathrm{s}^{-1}$ as it reached the end of the $150 \mathrm{~m} \times 150 \mathrm{~m}$ plot.

Our perspective and subsequent analysis of extreme fire behavior complement the observations of Radke et al. (2000), who first recognized these sudden flamefilled fingers and theorized that they were traveling near enough the ground to ignite the fuel. These fingers are present throughout our data as well, but our view of fires in profile allows us to refine their interpretations. Our analysis shows that the air in plumes initially bursts upslope parallel to the ground (at speeds of 28-48 $\mathrm{m} \mathrm{s}^{-1}$ ), close enough to ignite as well as to preheat and dry canopy fuel ahead of the fire. These observations support reports of "fireballs" or bursts of hot air (and flame) documented by firefighters overrun by crown fires. The flaming fingers next turn upward and accelerate to $50-60 \mathrm{~m} \mathrm{~s}^{-1}$, rising more vertically but tilted slightly downwind. If stronger environmental winds were bending the plume closer to the ground, even stronger along-ground components might occur. The purpose of the work is not merely to document that strong winds exist near a crown fire, but to shed light on how the atmosphere above the trees responds to and interacts with the tremendous energy of the fire. We emphasize that these phenomena are not explosions. The flames in wildland fires are purely gaseous deflagrations, not detonations, and are unconfined. In a confined deflagration (such as in a typical jet engine), volumetric expansion would strongly accelerate the flow.

These results clarify the mechanism for the rapid spread of crown fires. First, if the convective plume from 
(a)

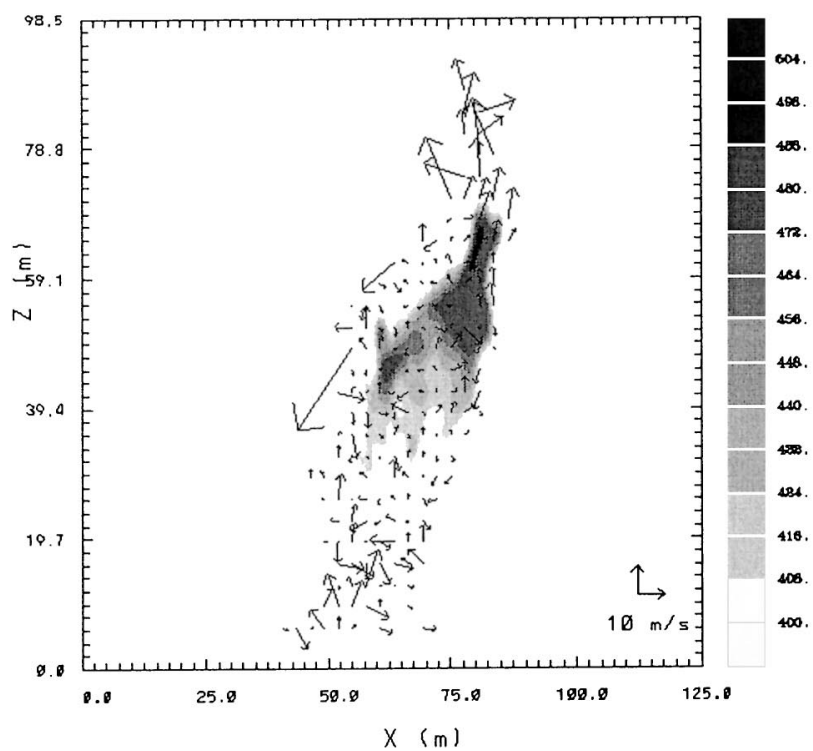

(b)

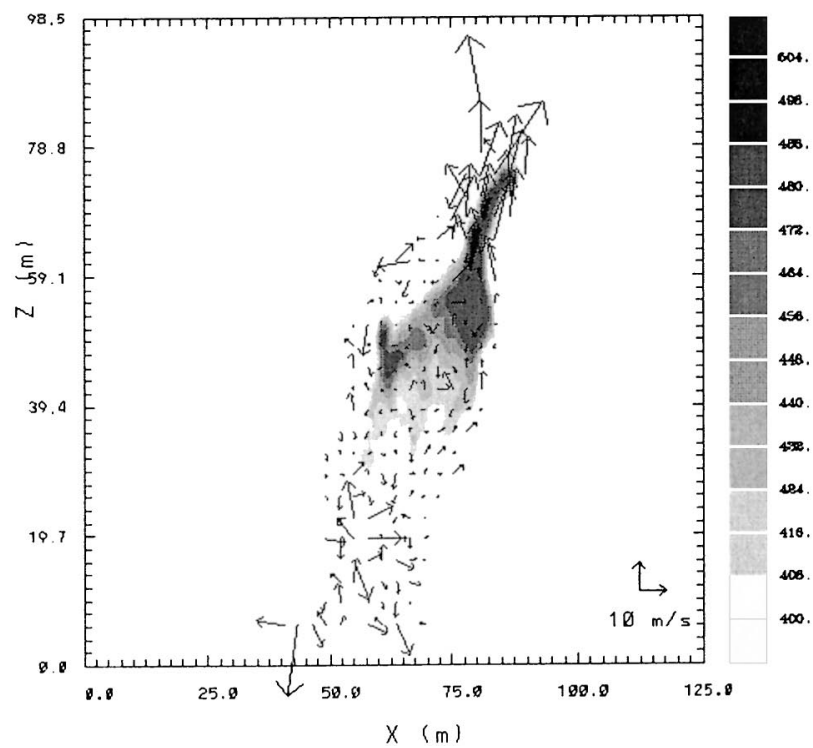

(c) TEMPERATURE $(\mathrm{deg} C)$
TIME $=12.917 \mathrm{sec}$

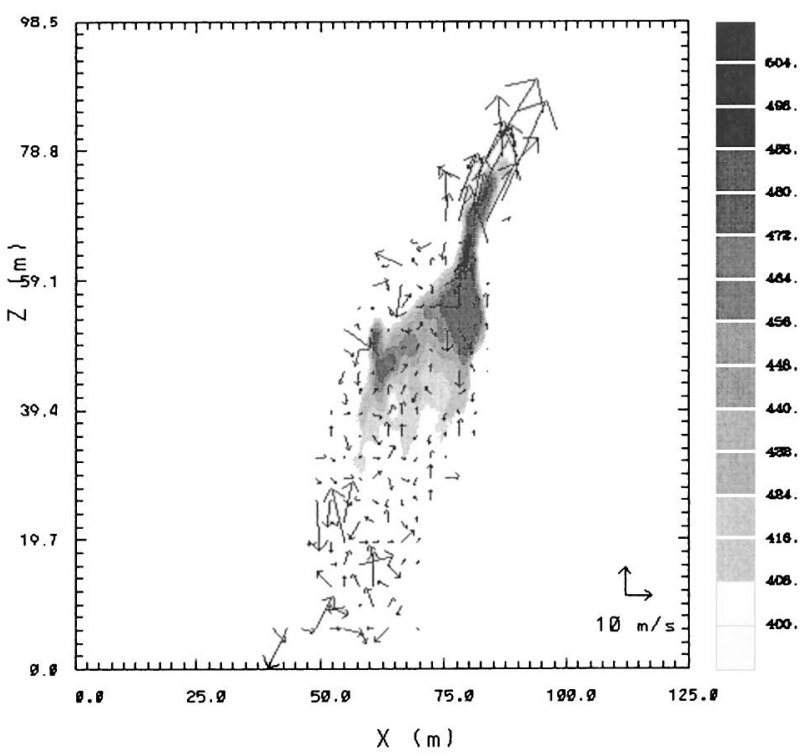

(d) TEMPERATURE ( deg C )
TIME $=13.067 \mathrm{sec}$

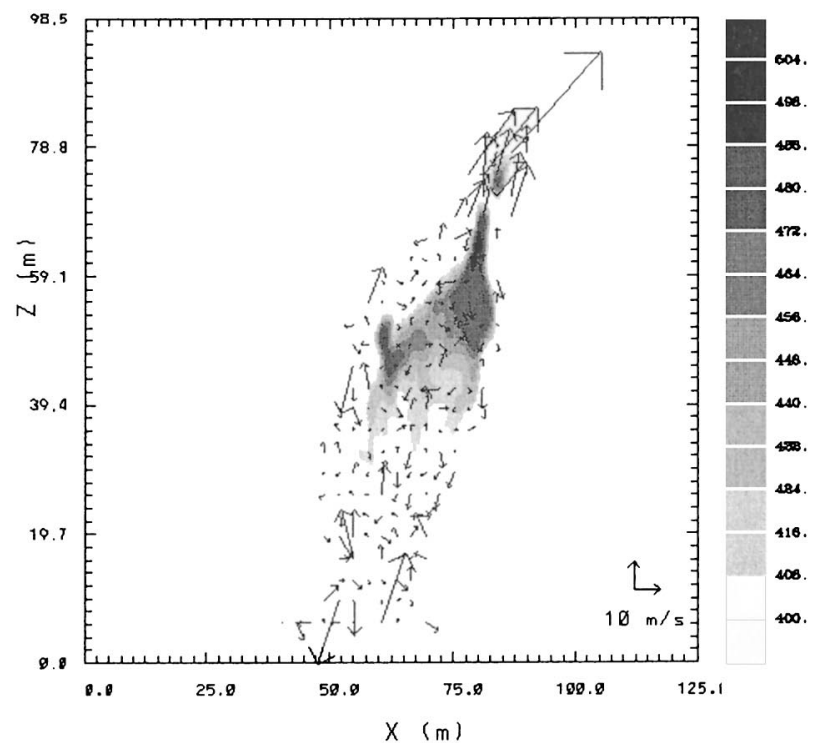

FIG. 10. Wind vectors derived through image-flow analysis of sequence 3 at four times: (a) 12.1, (b) 12.783, (c) 12.917, and (d) $13.067 \mathrm{~s}$. Shaded contours show the temperature detected by the infrared imager. Every eighth point in the $x$ direction and every fourth point in the $z$ direction are plotted.

the fire were merely rising because of buoyancy, such surges along the ground would not exist. The mechanism for rapid crown fire spread has been attributed (Rothermel 1991) to three factors: strong environmental winds (in the case of so-called wind-driven fires), downbursts of wind from convective cells, or momentum feedback from the vertical updraft increasing surface turbulence in the surface winds, resulting in increased radiational heating of surface fuels. None of these explanations is satisfactory here. First, the ambient flow is only $3 \mathrm{~m} \mathrm{~s}^{-1}$, even though bursts of $20-25 \mathrm{~m} \mathrm{~s}^{-1}$ were detected within $20 \mathrm{~m}$ of the ground (we cannot detect motions immediately next to the surface because it is obscured and the pixel temperature is diluted by trees). Second, no clouds were present to produce downdrafts. The source of the momentum was clearly not 
(a) TEMPERATURE 1 deg $\mathrm{Cl}$

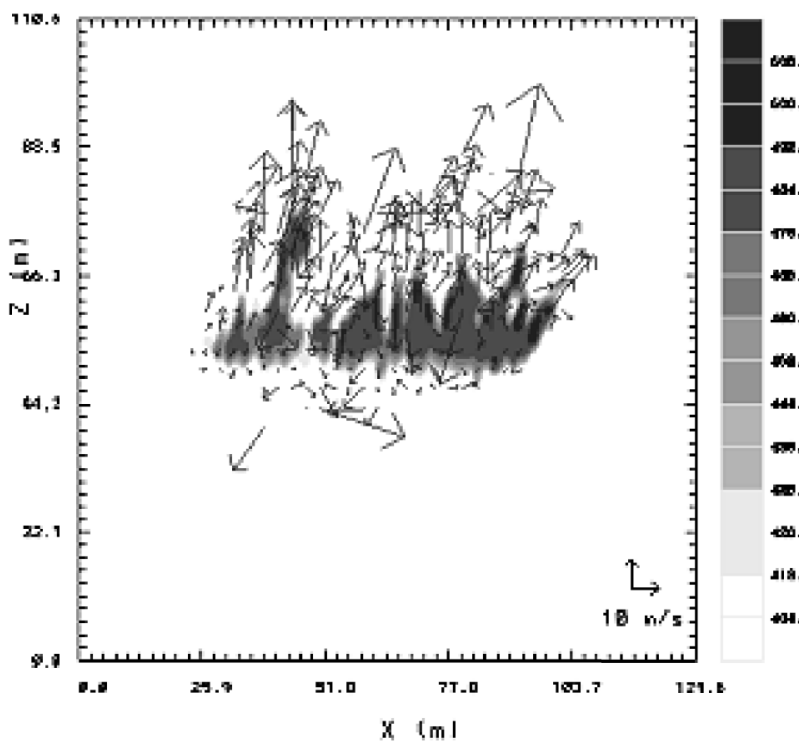

(b)

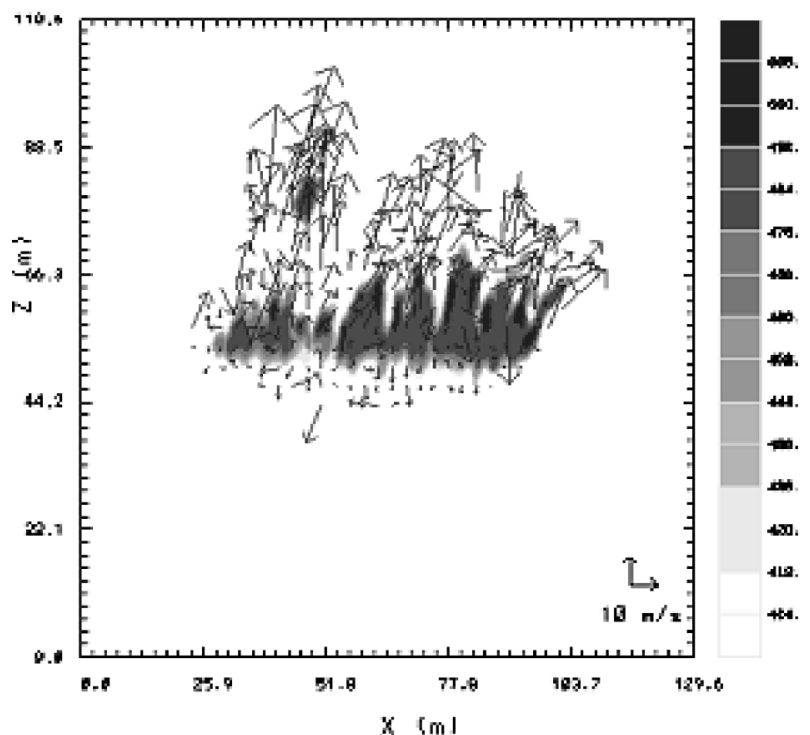

FIG. 11. Wind vectors derived through image-flow analysis of sequence 2 at two times: (a) 32.833 and (b) $33.067 \mathrm{~s}$. Shaded contours show the temperature detected by the infrared imager. Every eighth point in the $x$ direction and every fourth point in the $z$ direction are plotted.

these external environmental factors, but instead involved internal forces produced by the fire, including pressure gradients, advective terms, and buoyancy. The third explanation posed by Rothermel (1991) touches upon internal interactions, but the inflow to these extremely strong updrafts over a very narrow depth appears to be very organized and smooth, showing none of the signs of locally increased mixing-these bursts, although turbulent in nature, are coherent features. Other possible processes also can be discounted, such as the role of phase change on the fluid dynamics. Any phase change relating to pyrolysis of fuel is strictly a local effect, with a length scale of tens of centimeters near the solid fuel source, which is almost entirely attached to the ground. (There it is very important, because first vaporized water and then pyrolysis gases are driven rapidly from the solid fuel as it is heated radiatively.) Small amounts of fuel may be lofted by the fire, but they are energetically unimportant.

However, there are limits to this analysis; it cannot precisely identify how deep into the trees and close to the ground these forward-bursting fingers extend, because intervening treetops partially obscure our view, nor can this analysis tell how the flow is influenced by canopy drag.

Some unsettled points remain. This work provides insight into the downdrafts that supply the air that by mass conservation must be entering these convective updrafts. One would expect, from analogies to convective clouds, that intense convective columns would be surrounded by wider but relatively weaker compensating subsidence, yet here strong downdrafts that recirculated fire-modified air into the fire were detected. The phenomenon has implications for combustion reactions, because it could contain pyrolyzed but not ignited gaseous fuel or could reintroduce products of incomplete combustion back into the chemically active zones of the fire. However, because this imaging technique cannot detect clear air in the region of the fire and, with one instrument, is limited to a two-dimensional image plane, it cannot map the full three-dimensional atmospheric motions. This work also implies that, because of the highly nonlinear vortex dynamics, crown-fire behavior parameters such as spread rate are not likely to be parameterized adequately in terms of linear relationships among ambient wind speed, terrain slope, and vegetation characteristics.

We emphasize that the speed of extremely high temperature air near the surface is not based upon ambient wind speeds, but is a result of complex fire-atmosphere dynamics that transfer vertical momentum into surging flow along the surface. Clark et al. (1999) attributed the rapid forward burst of winds in a crown fire to vortex tilting in the sense that the tilted vortices (produced by sharp gradients in buoyancy) come together to form a hairpin shape, such that their combined motion results in tilting forward at a sharp angle, resulting in a turbulent burst. Some understanding of hairpin vortices may be drawn from Meinhardt and Adrian's (1995) discussion of boundary layers, in that repeated hairpin vortices form in shear layers in the overlying rapid flow and are stretched by the shearing action of the boundary layer because the tails remain in the low-speed region of the flow while the heads are entrained in the highspeed region. The vertical stretching, shown by the in- 
crease in vertical velocities with height in our data, would account for the high vertical rotation rates reported by Clark et al. (1999) in the counterrotating towers between which one burst reportedly occurred. However, we have also seen these bursts appear from narrow fires with a single updraft at the head.

However, these boundary layer phenomena are not a direct analogy, particularly because they do not involve buoyancy effects. Also, the temperatures in our results saturated the sensible temperature range (capped at $800^{\circ} \mathrm{C}$ ) and so combustion was still occurring-the transport and continued combustion of flammable gaseous pyrolysis products (which, according to our analysis, may also be recirculated into the convective updrafts) continues to release heat even as the buoyant air rises, adding complexity. Another added complexity is that the reaction rates in that process, based upon the knowledge of combustion in diffusion flames, are limited by the mixing rate of the envelope of flammable gases with air, where combustion is limited to the interface where stoichiometric conditions are met. Higher turbulence rates increase the mixing and thus the surface area of this interface (measured by the quantity "flame surface density") and overall heat release rates. Thus, the turbulence characteristics of this dynamic feature influence its strength. This is a difficult problem to study, because it requires modeling at scales that are extremely small for atmospheric models and extremely large for three-dimensional direct numerical simulation models of combustion. Nevertheless, these analyses provide data against which finescale numerical models, such as those of Porterie et al. (2003) and Linn et al. (2002), may be compared.

The domain-averaged quantities perhaps have the most application as an approximation of the net effect of the fire on the atmosphere. For example, the sensible heat flux averaged over the 141-m-long fire domain of sequence 5 gives an approximation for how such a fire might be represented in atmospheric prediction models. Because of the rapid rate at which this vertical heat flux decreases with height, it may be reasonable to approximate the macroscale effect of this fire on the atmosphere as a sensible heat flux of 1.0-1.2 $\mathrm{MW} \mathrm{m}^{-2}$ that peaks at $20-25 \mathrm{~m}$ above the ground but decays approximately exponentially above that, with an $e$-folding distance (where the value decreases to $e^{-1}$ or $\sim 37 \%$ of its value) at $11 \mathrm{~m}$ above the maximum. This cannot directly be contrasted with the $0.7-3.0 \mathrm{MW} \mathrm{m}^{-2}$ reported by Clark et al. (1999), because their perspective was from the front such that the fire filled the breadth of the image, whereas our perspective was in profile where the active head of the fire did not span the entire image, and they used ambient density $\left(1.0 \mathrm{~g} \mathrm{~kg}^{-1}\right)$ in their calculations rather than the local density (calculated as approximately $0.6 \mathrm{~g} \mathrm{~kg}^{-1}$ here). Nevertheless, the maximum sensible heat fluxes of 7-11 $\mathrm{MW} \mathrm{m}^{-2}$ represent an extreme for atmospheric processes, although very limited in extent and frequency.
Acknowledgments. Support for this work through NSF Grant ATM 0049007 to the University of California, Riverside, is gratefully acknowledged. The National Center for Atmospheric Research is sponsored by the National Science Foundation. We thank Larry Hinzman and John Gallagher at University of Alaska, Fairbanks, for providing the meteorological station data. We particularly thank the Alaska Fire Service for their assistance at the FROSTFIRE site. Comments and suggestions by two anonymous reviewers greatly improved the manuscript.

\section{REFERENCES}

Albini, F. A., 1993: Dynamics and modeling of vegetation fires: Observations. Fire in the Environment: The Ecological, Atmospheric, and Climatic Importance of Vegetation Fires, P. J. Crutzen and J. G. Goldhammer, Eds., John Wiley and Sons, 39-52.

—_ and B. J. Stocks, 1986: Predicted and observed rates of spread of crown fires in immature jack pine. Combust. Sci. Technol., 48, 65-76.

Bab-Hadiashar, A., and D. Suter, 1998: Robust optic flow computation. Int. J. Comput. Vision, 29, 59-77.

Bessie, W. C., and E. A. Johnson, 1995: The relative importance of fuels and weather on fire behavior in subalpine forests. Ecology, 76, 747-762.

Clark, T. L., M. A. Jenkins, J. Coen, and D. Packham, 1996a: A coupled atmospheric-fire model: Convective feedback on fire line dynamics. J. Appl. Meteor., 35, 875-901.

,,--- , and -1 , 1996b: A coupled atmospheric-fire model: Convective Froude number and dynamic fingering. Int. J. Wildland Fire, 6, 177-190.

— _ L. F. Radke, J. L. Coen, and D. Middleton, 1999: Analysis of small-scale convective dynamics in a crown fire using infrared video camera imagery. J. Appl. Meteor., 38, 1401-1420.

_ J. L. Coen, and D. Latham, 2004: Description of a coupled atmosphere-fire model. Int. J. Wildland Fire, 13, 49-63.

Coen, J. L., T. L. Clark, and D. Latham, 2001: Coupled atmospherefire model simulations in various fuel types in complex terrain. Preprints, Fourth Symp. on Fire and Forest Meteorology, Reno, NV, Amer. Meteor. Soc., 39-42.

Daily, J. W., S. Mahalingam, J. Milford, Y. Khunatorn, T. L. Clark, J. Coen, and L. Radke, 1999: Visible and IR imaging and UVvisible spectral analysis of the FROSTFIRE controlled burn near Fairbanks, Alaska, July 1999. Preprints, Spring Meeting Western States Section/The Combustion Institute, Golden, CO, The Combustion Institute, 1-12.

Drysdale, D., 1998: An Introduction to Fire Dynamics. 2d ed. John Wiley and Sons, $451 \mathrm{pp}$.

Dymess, C. T., T. K. Van Cleve, and J. D. Levison, 1989: The effect of wildfire on soil chemistry in four forest types in interior Alaska. Can. J. For. Res., 19, 1389-1396.

Farnebäck, G., 2001: Very high accuracy velocity estimation using orientation tensors, parametric motion, and simultaneous segmentation of the motion field. Proc. Eighth Int. Conf. on Computer Vision, Vancouver, BC, Canada, IEEE, 171-177.

_ 2002: Polynomial expansion for orientation and motion estimation. Ph.D. thesis, Linköping University, $182 \mathrm{pp}$.

Fastie, C. L., A. H. Lloyd, and P. Doak, 2003: Fire history and postfire forest development in an upland watershed of interior Alaska. J. Geophys. Res., 108, 8150, doi:10.1029/2001JD000570.

Hinzman, L. D., M. Fukuda, D. V. Sandberg, F. S. Chapin III, and D. Dash, 2003: FROSTFIRE: An experimental approach to predicting the climate feedbacks from the changing boreal fire regime. J. Geophys. Res., 108, 8153, doi:10.1029/2001JD000415. Linn, R., J. Reisner, J. J. Colman, and J. Winterkamp, 2002: Studying 
wildfire behavior using FIRETEC. Int. J. Wildland Fire, 11, 233246.

Meinhardt, C. D., and R. J. Adrian, 1995: On the existence of uniform momentum zones in a turbulent boundary layer. Phys. Fluids, 7, 694-696.

National Wildfire Coordinating Group, 1994: Introduction to wildland fire behavior S-190. National Interagency Fire Center NFES Workbook 180, 66 pp.

Porterie, B., J.-C. Loraud, L. O. Bellemare, and J.-L. Consalvi, 2003: A physically based model of the onset of crowning. Combust. Sci. Technol., 175, 1109-1141.

Radke, L. R., T. L. Clark, J. L. Coen, C. Walther, R. N. Lockwood, P. J. Riggin, J. Brass, and R. Higgins, 2000: The Wildfire Experiment (WiFE): Observations with airborne remote sensors. Can. J. Remote Sens., 26, 406-417.

Rothermel, R. C., 1983: How to predict the spread and intensity of forest and range fires. U.S. Dept. of Agriculture, Forest Service, Intermountain Research Station General Tech. Rep. INT-143, $161 \mathrm{pp}$

1991: Predicting behavior and size of crown fires in the northern Rocky Mountains. U.S. Dept. of Agriculture, Forest Service, Intermountain Research Station, Research Paper INT-438, 46 pp.

Verri, A., F. Girosi, and V. Torre, 1990: Differential techniques for optical flow. J. Opt. Soc. Amer., 7, 912-922.

Wang, H., and D. Suter, 2003: Variable bandwidth QMDPE and its application in robust optic flow estimation. Proc. Int. Conf. on Computer Vision, Nice, France, IEEE, 178-183.

Wilmore, R., K. Slaughter, M. Theisen, and J. Roessler, 1998: FROSTFIRE research prescribed burn plan. Bureau of Land Management Alaska Fire Service, 62 pp.

Zhou, X., L. Sun, D. Weise, and S. Mahalingam, 2003: Thermal particle image velocity estimation for fire plume flow. Combust. Sci. Technol., 175, 1-24. 